\title{
Computational Design of a Novel Medium-Carbon, Low-Alloy Steel Microalloyed with Niobium
}

\author{
Vahid Javaheri ${ }^{1}$, Tuomo Nyyssönen ${ }^{2}$, Bjørnar Grande ${ }^{3}$, David Porter ${ }^{4}$ \\ ${ }^{1}$ Corresponding author, Ph.D. student, Department of Material Engineering and Production Technology, University of \\ Oulu, Finland P.O. Box 4200 Email: Vahid.Javaheri@oulu.fi \\ 2 Postdoctoral researcher, Materials Science Research Group, University of Tampere, Finland Email: \\ tuomo.nyyssonen@tut.fi \\ ${ }^{3}$ R\&D Engineer, EFD Induction a.s, Norway Email: bjornar.grande@efd-induction.com \\ 4 Professor and Research Director, Department of Material Engineering and Production Technology, University of Oulu, \\ Finland Email: David.Porter@oulu.fi
}

\begin{abstract}
:
The design of a new steel with specific properties is always challenging owing to the complex interactions of many variables. In this work, this challenge is dealt with by combining metallurgical principles with computational thermodynamics and kinetics to design a novel steel composition suitable for thermomechanical processing and induction heat treatment to achieve a hardness level in excess of $600 \mathrm{HV}$ with the potential for good fracture toughness. CALPHAD-based packages for the thermodynamics and kinetics of phase transformations and diffusion, namely Thermo-Calc ${ }^{\circledR}$ and $\mathrm{JMatPro}^{\circledR}$, have been combined with an interdendritic segregation tool (IDS) to optimize the contents of chromium, molybdenum and niobium in a proposed medium-carbon low-manganese steel composition. Important factors taken into account in the modelling and optimization were hardenability and as-quenched hardness, grain refinement, and alloying cost. For further investigations and verification, the designed composition, i.e. in wt. $\% 0.40 \mathrm{C}, 0.20 \mathrm{Si}, 0.25 \mathrm{Mn}, 0.90 \mathrm{Cr}$, $0.50 \mathrm{Mo}$, was cast with two nominal levels of $\mathrm{Nb}$ : 0 and $0.012 \mathrm{wt} . \%$. The results showed that an addition of $\mathrm{Nb}$ decreases the austenite grain size during casting and after slab reheating prior to hot rolling. Validation experiments showed that the predicted properties i.e. hardness, hardenability and level of segregation for the designed composition were realistic. It is also demonstrated that the applied procedure could be useful in reducing the number of experiments required for developing compositions for other new steels.
\end{abstract}

Keywords: Computational design, Wear resistance steel, CALPHAD, Thermo-Calc ${ }^{\circledR}$, IDS, JMatPro, Microsegregation, Homogenization, Prior austenite grain size 


\section{1- Introduction}

Steel has played and will continue to play a major role in the development of modern societies [1-3]. Materials scientists continue to devote themselves to the development of new steels in order to meet the ever-increasing demands for better performing steels [4-7]. The design of new steels with desired combinations of sometimes contradictory properties is a challenging task as many variables and their complex interactions should be taken into account. For example, in the case of steel pipeline for the transport of slurries and cement in the mining and construction industries, pipe service life benefits from high resistance to erosion (wear) and corrosion, combined with sufficient toughness. In many slurry transport applications, the main failure mechanism determining the slurry equipment life is erosion rather than corrosion [8-11] and it has been shown that longer service lives are obtained with higher hardness on the working (inner) surface [12-15].

Also, for a given hardness and chemical composition, a tougher microstructure could have a better resistance to erosion by brittle mechanisms as shown by O'Flynn et al. [15].Toughness is also important with regard to the ability of the pipe to withstand loads without fracture. More accurately, the slurry pipe will benefit from good fracture toughness, i.e. resistance to cleavage fracture, and good tensile ductility, i.e. elongation to fracture in tensile testing. Sufficient fracture toughness helps the pipe tolerate various internal defects without brittle fracture under the external loads and impacts that arise during handling, installation and maintenance [16]. In buried pipelines, tensile ductility and fracture toughness help in the tolerance of differential soil movements as well.

Erosion resistant pipes can be cost-effectively produced using high-frequency (HF) induction welding of skelp produced using thermomechanical controlled processing on a hot strip mill [17]. By combining induction hardening and subsequent quenching of HF welded pipe, it may be possible to produce a gradient of mechanical properties through the pipe wall thickness. Suitable thermomechanical processing parameters may allow the attainment of high hardness to deeper in the pipe wall, without a loss of toughness, thereby extending the useful life of the pipe.

For erosion resistance, it has been shown that good performance can be achieved with martensitic microstructures having a hardness of about $600 \mathrm{HB}$, corresponding to $630 \mathrm{HV}$ or 57 HRC [16]. Such a hardness level can be obtained in a pipe by using induction hardening to a fully martensitic microstructure with a carbon content of about 0.40 wt.\% $[18,19]$. It has also long been known that high strength, i.e. high hardness, with high toughness can be obtained by reducing grain size, and, in the case of low-carbon steels containing up to about $0.2 \% \mathrm{C}$, this is effectively and efficiently obtained through the use of niobium microalloying combined with heat treatment or thermomechanical treatment [20,21]. However, there is very little experience in the use of $\mathrm{Nb}$ microalloying in steels containing about 0.4 wt. \% C.

The work described in this paper is the first step in a project aimed at exploring the possibilities of combining thermomechanical processing and induction heat treatment to improve the hardness - toughness combinations that can be obtained in a medium-carbon steel for possible application in slurry pipes. We are concerned with the design of a steel chemistry that would be suitable for the following production route: continuous casting, hot strip rolling and coiling, slitting into skelp, cold forming and high-frequency induction welding 
into pipe followed by induction heat treatment to give a hard inner pipe surface combined with a tough pipe body. The paper describes how commercially available software can be combined with empirical metallurgical knowledge to design a steel composition with the potential of being amenable to the above production process. The paper is based on the assumption that hardness is the main factor governing the service life of a slurry pipe and an aim hardness of $600 \mathrm{HB}$ forms the basis of the approach. The potential use of the composition in thermomechanical processing led to an extensive consideration of microalloying with niobium.

The approach is based on the use of software that relates chemical composition to hardness, hardenability and microsegregation. Combining these with considerations of the cost of alloying led to an optimized chemical composition that was subsequently cast and experimentally evaluated to verify the reliability of the calculations with respect to hardness and hardenability. Factors detrimental to toughness arising at the solidification stage, i.e. microsegregation and inclusion formation, are taken into account in the composition design, but toughness properties as such are not covered in the paper as they depend on the subsequent processing of the cast material. The actual toughness - hardness combinations that can be obtained after thermomechanical and heat treatments will be the topic of future publications as will the erosive wear properties.

While the background to this paper lies in the exploration of new ways to manufacture better slurry pipe, the approach and metallurgical considerations described are generally valid for the design of other medium-carbon steels requiring good combinations of strength, hardness and toughness where $\mathrm{Nb}$ microalloying, thermomechanical rolling and induction heat treatment provide a potential manufacturing route.

\section{2- Computational Details}

In this work, JMatPro ${ }^{\circledR}$ software was used for the prediction of Time-TemperatureTransformation (TTT) and Continuous Cooling Transformation (CCT) diagrams for austenite decomposition as well as hardness and microstructure predictions. IDS software (InterDendritic Segregation) and the Thermo-Calc ${ }^{\circledR}$ packages SCHEIL and DICTRA combined with the TCFE9 thermodynamic database and the MOBFe2 mobility database were used to predict the microsegregation that occurs during solidification. For this purpose, it was assumed that the cooling rate through the solidification temperature range is $1{ }^{\circ} \mathrm{C} / \mathrm{s}$ and the secondary dendrite arm spacing $100 \mu \mathrm{m}$. DICTRA was also used for calculating the degree of homogenization during slab reheating (more details in the section 3-6).

It has to be remarked that DICTRA is a finite element based program for simulation of DIffusion-Controlled TRAnsformations like segregation. It assumes a local equilibrium at the moving phase interface and uses comprehensive databases with full integration of thermodynamics and kinetics data [22]. Also, both Thermo-Calc SCHEIL and the IDS ${ }^{\circledR}$ software calculate interdendritic segregation during solidification. They assume a uniform solute distribution and perfect mixing in the liquid phase, i.e. infinitely fast diffusion of all alloying components in the liquid phase, which is usually realistic owing to the high atomic mobility in the liquid [23]. The situation is different with regard to the assumptions regarding 
solid state diffusion where, in the case of the Thermo-Calc SCHEIL software, only the rapid diffusion of the interstitial solutes $\mathrm{C}$ and $\mathrm{N}$ in the solid is taken into account and the assumption is made that substitutional atom diffusion is negligible. However, this is a poor assumption in the case of solidification involving ferrite in which diffusion is relatively fast [24]. A more realistic approximation would be given by using Thermo-Calc DICTRA software, but this is rather time-consuming. IDS ${ }^{\circledR}$, on the other hand, takes into account diffusion of all alloying elements in the solid phase in combination with the assumption of local equilibrium at phase interfaces. Both Thermo-Calc and IDS assume that, during solidification, a new phase begins to form as soon as it is thermodynamically possible [25]. In addition to interdendritic solidification, the $\operatorname{IDS}^{\circledR}$ software also predicts the phase transformations occurring in the cast material from the melt down to room temperature [25].

\section{3- Composition Design Methodology}

A flow chart representing the methodology for the design of the alloy composition is given in Fig. 1. The alloy design process started with the choice of the steel family based on application as a pipeline material, and then choosing the amounts of carbon, silicon, and manganese. Subsequently, a range of chromium and molybdenum contents was studied to optimize their contents with respect to the balance of microstructure, hardness and alloying cost. It should be remarked that chromium is a low-cost route to hardenability and it is also beneficial for slurry transportation due to improved corrosion resistance [26]. Molybdenum increases hardenability and it can increase the ultimate and yield strength as well [27]. Finally, computational thermodynamics combined with microsegregation calculations were used to optimize the amount of niobium from the point of view of avoiding interdendritic eutectic $\mathrm{NbC}$ formation and dissolving all niobium prior to hot rolling. Niobium microalloying was considered desirable from the point of view of prior austenite grain refinement, both during thermomechanical processing and induction heat treatment. Finer prior austenite grains lead to finer martensitic and bainitic microstructures, i.e. improved Charpy $V$ and fracture toughness in the heat-treated pipe [28-30]. The considered rationale for each step is described in the following sub-sections.

\section{3-1- Carbon content}

Simply, to achieve a hardness of at least $600 \mathrm{HB}$ in the fully martensitic state together with reasonable toughness, a medium carbon content of 0.40 wt. \% was chosen [31].

\section{3-2- Silicon content}

Silicon can increase the carbon content in retained austenite by hindering the precipitation of cementite, which can have beneficial effects on toughness: however, it has a strong tendency to segregate to grain boundaries and reduce toughness [32,33]. It has been widely reported that, in medium-carbon low-alloyed steel especially after tempering, a significant increase in toughness can be obtained with Si contents below 0.30 wt.\% [34,35]. Therefore, a low amount of 0.20 wt. \% Si was selected. 


\section{3-3- Manganese content}

In addition to achieving high hardness in the steel, it is desirable to achieve as high a toughness as possible. It is envisaged that the inner surface of the pipe will be fully martensitic with only modest toughness, but deeper into the pipe wall thickness the microstructure will also contain bainite. The toughness of bainitic microstructures is sensitive to the presence of microsegregation. As will be shown below, the solidification of $0.4 \% \mathrm{C}$ low-alloy steels results in the formation of a high fraction of austenite from the liquid phase, which increases the tendency for microsegregation to occur compared to the solidification to ferrite characteristic of low-carbon steels. Microsegregation easily prevails in the final product and thermal cycles that result in fully bainitic microstructures in homogeneous alloy compositions can become banded mixtures of bainite and martensite in the presence of the fluctuating alloy contents caused by microsegregation. It has been shown that this can halve the impact toughness for a given level of strength or hardness in a high-manganese medium-carbon steel [36].

Manganese is known to be particularly susceptible to microsegregation [37] and under unfavourable casting conditions, microsegregation combined with interdendritic liquid flow can lead to macrosegregation [38]. This is undesirable in high-frequency welded pipe as the upsetting process involved bends the skelp centreline parallel to the weld fusion line, which is detrimental to the toughness of the weld [17]. The benefits of low manganese in respect of microsegregation will carry over into reduced macrosegregation and better weld toughness properties as well.

Furthermore, manganese sulphide inclusions tend to elongate during hot rolling, which is also detrimental to toughness, both in the bulk and particularly when aligned along the weld fusion line. Modern steelmaking practices make it possible to achieve very low sulphur contents and calcium treatment leads to the formation of complex hard spherical oxysulphide inclusions that do not elongate during rolling [39]. However, disturbances in steelmaking can nevertheless lead to the formation of MnS inclusions. With lower manganese content MnS forms from the liquid closer to the solidification temperature producing smaller particles [40]. Since the plasticity of MnS inclusions in the hot rolling process increases directly with increasing Mn level [17], lowering the Mn content should reduce the deformability of the inclusions, thereby reducing the final aspect ratio, too. Considering all of the above factors a low level of $0.25 \mathrm{wt}$.\% $\mathrm{Mn}$ has been chosen for the current application.

\section{3-4- Chromium and molybdenum contents}

In order to determine the optimal amount of $\mathrm{Cr}$ and $\mathrm{Mo}$, ten simulations have been run using JMatPro ${ }^{\circledR}$ software, with the $\mathrm{Cr}$ and Mo contents given in Fig. 2. For these calculations, the grain size and austenitization temperature have been assumed to be ASTM 8 and $950^{\circ} \mathrm{C}$, respectively. The selected range of Mo was varied from 0.30 to $0.90 \mathrm{wt}$. \% (four levels) and a range of 0 to $1 \mathrm{wt} . \%$ (three levels) was defined for $\mathrm{Cr}$. For the reasons explained above, the contents of the other alloying elements were fixed at $0.4 \mathrm{wt} . \% \mathrm{C}, 0.25 \mathrm{wt} . \% \mathrm{Mn}, 0.20$ 
wt.\% Si. In addition, a $\mathrm{Nb}$ content of $0.012 \mathrm{wt} . \%$ was assumed, for the reasons described below (section 3-5). The results of these calculations are presented in Table 1. It can be seen that the hardenability parameters and hardness level vary with composition. As observed, the highest hardness level was predicted for alloy No. 8, but it did not have a best condition regarding the hardenability. Therefore, to determine the best combination of chromium and molybdenum based on the alloy design criteria (hardness, hardenability and cost), multiple linear regression analyses including interaction terms were made using the results in Table 1. Some of the outcomes are summarized in Figs. 3-4.

Fig. 3 shows that according to $\mathrm{JMatPro}^{\circledR}$, for the studied composition window, the highest martensite hardness should be achievable with a high $\mathrm{Cr}$ content combined with a low concentration of Mo; however, Mo could suppress the formation of polygonal ferrite and pearlite and increase the hardenability at lower cooling rates [41]. Therefore, the best combination of $\mathrm{Cr}$ and Mo was determined by following the procedure described in the next paragraph.

In order to achieve martensite on the inner surface of the pipe during quenching, bainite formation must be avoided. In this case, we have taken the critical cooling rate at the bainite nose $(\mathrm{CR}(\mathrm{Bn}))$ as $45^{\circ} \mathrm{C} / \mathrm{s}$. As far as alloying costs are concerned, this condition can be best met with a high level of $\mathrm{Cr}$ and a low Mo content. (The alloying cost of each combination of $\mathrm{Cr}$ and $\mathrm{Mo}$ is presented in the background contour plot of Fig. 4 based on the fact that, on a mass basis, molybdenum is approximately 10 times more expensive than chromium). However, as can be seen from Fig. 4, as the Mo content is lowered while keeping the condition $\mathrm{CR}(\mathrm{Bn})=45^{\circ} \mathrm{C} / \mathrm{s}$, the tendency to form ferrite increases. Ferrite will be associated with low hardness and strength deeper in the pipe wall and in order to reduce the steepness of the hardness gradient in the thickness direction, it was decided to set the cooling rate for the ferrite nose to $10^{\circ} \mathrm{C} / \mathrm{s}$. Together, these conditions resulted in $0.90 \mathrm{wt} . \% \mathrm{Cr}+0.50 \mathrm{wt} . \%$ Mo as giving the most desirable combination.

\section{3-5- Niobium content}

Grain refinement strengthening is the most common way to simultaneously improve both hardness and toughness [28-30]. The most popular way to achieve grain refinement in steels is through microalloying. As mentioned above, $\mathrm{Nb}$ was chosen as a microalloying element because of its strong grain refining ability during both austenitization heat treatment and thermomechanical rolling [42-45]. However, it tends to partition to interdendritic regions along with $\mathrm{C}$ which can result in the formation of large eutectic $\mathrm{NbC}$ particles $[46,47]$.

Heikkinen and Packard [48] showed that for $0.06-0.24 \% \mathrm{C}$ a small amount of $\mathrm{Fe}+\mathrm{NbC}$ eutectic is formed for all niobium contents in the range $0.02-0.17 \%$, with the amount of $\mathrm{NbC}$ eutectic increasing with increasing contents of niobium and carbon. It was also showed that eutectic $\mathrm{NbC}$ remains undissolved during typical simulated slab reheating of $3 \mathrm{hrs}$ at 1240 ${ }^{\circ} \mathrm{C}$ and that the eutectic particles become elongated inclusion stringers during hot rolling. Undissolved eutectic $\mathrm{NbC}$ particles may well be detrimental to toughness of the pipe body and especially the weld line as segregation and eutectic formation can be expected to be greatest on the strip centerline. Matsui, Sato and Tanaka [49] showed that for 0.11 to $0.26 \%$ $\mathrm{C}$ and 0.02 to $0.07 \% \mathrm{Nb}$, the sum (\% C $+2.5 \times \% \mathrm{Nb}$ ) must exceed a critical level for eutectic 
$\mathrm{NbC}$ to appear. The critical level was found to be dependent on the cooling rate through the liquidus - solidus range, but independent of other alloying elements such as $\mathrm{Si}, \mathrm{Mn}, \mathrm{Cr}, \mathrm{Ni}$, $\mathrm{V}$, and Mo. In the studies of Heikkinen and Packard, and Matsui et al, the carbon content of the steel was about $0.25 \%$ at most. In the present case, the carbon content is considerably higher at $0.40 \%$. This higher carbon content will exacerbate the formation of $\mathrm{NbC}$ eutectic through two effects: 1) the higher carbon content per se and 2) the fact that higher carbon means solidification to a higher fraction of austenite from the liquid, which increases the partitioning of $\mathrm{Nb}$ and $\mathrm{C}$ into the interdendritic spaces. For this reason, careful consideration had to be given to the choice of $\mathrm{Nb}$ content in the present case.

Fig. 5 shows the results of solidification simulation for the considered composition $(0.40 \mathrm{C}$, $0.20 \mathrm{Si}, 0.25 \mathrm{Mn}, 0.90 \mathrm{Cr}, 0.50 \mathrm{Mo}, 0.016 \mathrm{Nb}$, \%wt.) using Thermo-Calc ${ }^{\circledR}$ SCHEIL and IDS ${ }^{\circledR}$ software [25]. As expected, the Scheil analysis (solid line) predicted a much greater solidification range than the IDS ${ }^{\circledR}$ simulation (dashed line). The Scheil calculation indicted the formation of eutectic $\mathrm{NbC}$ during solidification as $\mathrm{Nb}$ back diffusion is ignored, while taking back diffusion into account with the IDS software no $\mathrm{NbC}$ eutectic formation is predicted for the $\mathrm{Nb}$ content of $0.016 \mathrm{wt} \%$. The IDS model is based on more realistic empirical assumptions and it was chosen for a deeper exploration of the effect of $\mathrm{Nb}$ content as shown in Fig. 6. Microsegregation during solidification leads to a continuous increase in the $\mathrm{Nb}$ content in the liquid phase up to the final solidification point, i.e. the non-equilibrium solidus temperature. For 0.06 and $0.08 \mathrm{wt} . \% \mathrm{Nb}$, the concentration of $\mathrm{Nb}$ in the interdendritic liquid passes the threshold for eutectic formation, i.e. the red line in the Fig. 6. Therefore, it should be possible to consider $\mathrm{Nb}$ contents up to 0.04 wt.\% without any eutectic $\mathrm{NbC}$ formation. But, there are two other considerations to be taken into account regarding the choice of $\mathrm{Nb}$ : one related to thermomechanical processing and the other induction heating prior to hardening.

The amount of $\mathrm{Nb}$ should be suitable for thermomechanical processing, i.e. the formation of fine grained deformed austenite with a high specific grain boundary area giving fine bainitic microstructures after coiling. The chosen $\mathrm{Nb}$ content should also retard austenite grain growth during the induction heating of the cold-formed pipe product prior to hardening. For these purposes, the $\mathrm{Nb}$ should be taken into solution during slab reheating but remain undissolved when austenitizing during induction heat treatment.

Regarding thermomechanical rolling, conventional structural steels microalloyed with $\mathrm{Nb}$ contain for example $0.1 \mathrm{wt} \% \mathrm{C}$ and $0.04 \mathrm{wt} . \% \mathrm{Nb}$, which leads to supersaturation with respect to the precipitation of $\mathrm{NbC}$ (or $\mathrm{Nb}(\mathrm{CN})$ ) over the range of temperatures typically encountered in thermomechanical rolling, say $1150-750{ }^{\circ} \mathrm{C}$ [50]. Another example is 0.04 wt.\% C together with 0.09 wt.\% Nb, which is used for example in the production of thermomechanical rolling [51]. The solvus temperature for $\mathrm{NbC}$ in austenite for both these cases will be approximately the same as it depends on the product [wt.\% $\mathrm{Nb}] \times$ [wt.\% C]. Using the solubility formula of Ref. [52] and a typical Mn content of $1.5 \mathrm{wt}$. $\%$ gives the solvus temperatures of the 1087 and $1073{ }^{\circ} \mathrm{C}$ respectively for the previous examples. Below the solvus temperature, there is a driving force for precipitation of $\mathrm{NbC}$ and at sufficiently high driving forces the precipitation is able to inhibit recrystallization during thermomechanical rolling. Thus, it is necessary to consider the effect of $\mathrm{Nb}$ content and other alloying elements on the $\mathrm{Nb}$ solvus temperature for the steel chemistry under consideration. IDS simulations 
of the microsegregation of $\mathrm{Nb}$ in the solid phase in the steel composition given in Table 2 during and after solidification for a cooling rate of $1^{\circ} \mathrm{C} / \mathrm{s}$ are presented in Fig. 7.

Fig. 7 shows that the concentration of $\mathrm{Nb}$ solidifying as austenite increases as the temperature drops and interdendritic segregation proceeds until the end of solidification and, then, as the temperature decreases further, back diffusion leads to a reduction of the $\mathrm{Nb}$ concentration in the austenite formed from the last liquid to solidify. As can be seen from the figure, the calculated final interdendritic concentrations of $\mathrm{Nb}$ in solution in the austenite after cooling to approximately $1200{ }^{\circ} \mathrm{C}$ are approximately 2.2 times greater than the mean bulk $\mathrm{Nb}$ concentration, i.e. 0.026/0.012, 0.035/0.016, 0.044/0.020 and 0.089/0.04. Below 1200 ${ }^{\circ} \mathrm{C}$ there is no significant further homogenisation of the cast material. Ignoring the changes in $\mathrm{Nb}$ concentration caused by slab reheating, as mentioned earlier, it is desirable to be able to redissolve the $\mathrm{Nb}$ during reheating prior to hot rolling in order to be able to achieve the precipitation of fine $\mathrm{NbC}$ in the austenite and prevent recrystallization throughout the matrix. Therefore, a typical slab reheating temperature of say $1200^{\circ} \mathrm{C}$ should be above the solvus temperature even for the interdendritic positions. Fig. 8 shows the $\mathrm{NbC}$ solvus temperature as a function of $\mathrm{Nb}$ for the predicted interdendritic composition of the chosen alloy (from Table 2). It can be seen that an interdendritic concentration of $0.026 \mathrm{wt} . \% \mathrm{Nb}$ (corresponding to a bulk content of $0.012 \mathrm{wt} \% \mathrm{Nb}$ ) could be taken into solution during reheating to 1200 ${ }^{\circ} \mathrm{C}$. Therefore, a bulk level of $0.012 \mathrm{Nb}$ was chosen as a suitable microalloying level for the intended application. It should be noted that Ref [52] also predicts the solvus temperatures similar to those predicted by Thermo-Calc. In the case of the chosen bulk content of 0.012 $\% \mathrm{Nb}$, Thermo-Calc predicts the solvus temperature to be $1109{ }^{\circ} \mathrm{C}$, which is close to the values quoted above for typical thermomechanically processed low-carbon steels (1087 and $1073^{\circ} \mathrm{C}$ ). This indicates that there will be a suitable driving force for $\mathrm{NbC}$ precipitation during the thermomechanical processing of the chosen composition. Of course, the total amount of $\mathrm{Nb}$ available to precipitate will be lower when the total is not more than $0.012 \mathrm{wt} \%$. However, the effectiveness of $\mathrm{Nb}$ in retarding recrystallization will be increased by the presence of 0.5 wt.\% Mo [53]. Table 2 shows the complete bulk composition together with the concentrations of the alloying elements at the last solidifying locations.

In the case of the austenitization of conventional quenched and tempered steels, $\mathrm{NbC}$ precipitates are able to hinder austenite grain growth and thereby improve impact toughness transition temperature as shown by Hulka et al [54]. Typical levels of $\mathrm{C}$ and $\mathrm{Nb}$ in quenched and tempered structural steels are 0.14 and 0.025 wt.\% respectively. Using Ref [52] together with a typical Mn content of 1 wt. \% gives a solvus temperature of $1085{ }^{\circ} \mathrm{C}$. This is very similar to the above cases quoted for thermomechanically processed steels. Typical austenitizing temperatures prior to quenching, e.g. $900{ }^{\circ} \mathrm{C}$, are well below the solvus temperature such that most of the $\mathrm{Nb}$ is present as $\mathrm{NbC}$ precipitates. Again, this is evidence supporting the choice of 0.012 wt. $\% \mathrm{Nb}$ combined with $0.4 \mathrm{wt} \% \mathrm{C}$ for the present application.

\section{3-6- Slab Reheating Simulation}

Generally, slab reheating should lead to some homogenisation of the $\mathrm{Nb}$ content in addition to the back diffusion occurring during solidification. DICTRA was employed to simulate the 
extent of homogenization that can be expected after various holding times at a slab reheating temperature of $1200{ }^{\circ} \mathrm{C}$. The homogenization was simulated using a computational cell defined as the half-width of the secondary dendritic arm spacing [22,55]. Meanwhile, the composition profiles from the solidification process defined the initial composition profiles for the homogenization simulations. The $\mathrm{Nb}$ concentration during homogenization treatment for different holding times $\left(0.1,1,2,4\right.$, and 8 hours) at $1200^{\circ} \mathrm{C}$ is given in Fig. 9. It can be seen that the niobium concentration should be quite uniform after 4 to $8 \mathrm{~h}$ holding at $1200{ }^{\circ} \mathrm{C}$. Even $1 \mathrm{~h}$ at $1200{ }^{\circ} \mathrm{C}$ should reduce the peak interdendritic concentration of $\mathrm{Nb}$ from 0.026 to $0.021 \mathrm{wt} \%$, which means that, actually, higher concentrations of $\mathrm{Nb}$ than the chosen $0.012 \mathrm{wt}$ \% could be taken into solution during slab reheating if the reheating schedule can be designed to consistently give a specified minimum holding time of $1 \mathrm{~h}$ at $1200^{\circ} \mathrm{C}$. However, if holding time at peak temperature during slab reheating is subject to variations due to practical production and productivity considerations, the choice of $0.012 \mathrm{wt} . \%$ will be safe from the point of view of the dissolution of all $\mathrm{Nb}$ prior to rolling. As mentioned above, it will also avoid the formation of relatively large eutectic particles. The situation with regard to the homogenization of other alloying elements during the slab reheating is presented in Fig. 10. The figure shows that $\mathrm{Nb}$ homogenization is predicted to be clearly faster than that of the other substitutional alloying elements, which is because $\mathrm{Nb}$ is one of the fastest diffusing elements in $\mathrm{Fe}$ and $\mathrm{Fe}$ alloys [56].

\section{4- Preliminary Experimental Validation}

The aim of this work was to design a steel composition potentially suitable for slurry pipe applications after thermomechanical processing and induction heat treatment. Future work will be aimed at in-depth studies of the effects of thermomechanical processing and induction heat treatment on the microstructure, hardness, strength, ductility and toughness of the designed composition. The results will be used to select processing parameters for the production of microstructures for slurry pot testing [57]. To enable this experimental programme, laboratory casts of the designed composition have been made as described below.

Since the design was partly based on predictive software, it is also of interest to assess the validity and accuracy of the predictions using the cast material. As is clear from above, the main issues have been concerned with 1) the use of JMatPro software to select alloy element contents giving a certain hardenability and martensite hardness, and 2) the use of IDS and Thermo-Calc software to select an appropriate $\mathrm{Nb}$ content taking into account the effects of microsegregation and diffusion during casting. In this section, some results concerning the accuracy of the software predictions are presented. The suitability of the steel composition to the intended processing and its performance with respect to slurry erosion properties will be the subject of future work.

As there is relatively little experience with the use of $\mathrm{Nb}$ in medium-carbon steels, it was decided to examine the effect of $\mathrm{Nb}$ by making casts according to the bulk composition in Table 2, but both with and without the $\mathrm{Nb}$ addition. The casts were produced using a vacuum-induction melting (VIM) furnace to ensure very low impurity levels. Liquid metal was 
cast into a closed-bottom cast iron mould with internal dimensions: $51 \times 310 \times 600 \mathrm{~mm}$. To check the hardness and hardenability, induction hardening of a hot-rolled sample has been simulated using a Gleeble 3800 thermomechanical simulator with two different cooling rates of 10 and $45^{\circ} \mathrm{C} / \mathrm{s}$ and an austenitization temperature of $950{ }^{\circ} \mathrm{C}$.

In order to reveal microstructural features, standard metallographic techniques including sectioning, grinding, polishing, and etching were applied followed by laser scanning confocal and scanning electron microscopy. A $2 \%$ nital solution was used to reveal the microstructure and deep etching in a saturated aqueous picric acid solution with a few drops of detergent and hydrochloric acid was utilized to reveal the dendritic structure. Microsegregation was characterised by analysing elemental distributions with the aid of an electron microprobe equipped with a wavelength dispersive spectrometer (WDS) and an energy dispersive Xray spectrometer (EDS). (JXA-8200 Superprobe). Moreover, a field emission scanning electron microscope (Zeiss Sigma FESEM) equipped with electron backscatter diffraction (EBSD) was employed to investigate the features of the parent austenite and the final grain structures.

\section{4-1- Secondary dendrite arm spacing}

As the secondary dendritic arm spacing should be considered carefully when carrying out computer modelling of solidification, the dendritic structure of the center-line of the casting was studied using laser scanning confocal microscopy. Numerous measurements revealed that the average secondary dendritic arm spacing was indeed around $100 \mu \mathrm{m}$, as shown by the example given in Fig. 11(a). This is what was predicted by IDS for the used cooling rate of $1{ }^{\circ} \mathrm{C} / \mathrm{s}$. A dendritic structure is characterised by the primary and secondary dendrite arm spacings and the orientations of the dendrites that result in the formation of grain boundaries as schematically illustrated in Fig. $11(\mathrm{~b})$.

\section{4-2- Grain Size}

The main purpose of the $\mathrm{Nb}$ addition is grain refinement during hot rolling due to the increase of the non-recrystallization temperature and restriction of grain growth during the austenitization owing to the pinning effects of $\mathrm{NbC}$ precipitates. The IDS simulations revealed that $\mathrm{Nb}$ should also refine the solidified grain size by restricting grain growth during cooling of the casting, see Fig. 12. The precipitation of $\mathrm{NbC}$ in the casting after solidification is the main reason for such a decrease in the as-cast grain size as the grain size and grain growth are mainly affected by the solidification cooling rate and also the pinning effect of precipitates [58].

High resolution EBSD was used to measure and quantify the grain size of the parent austenite and final martensitic - bainitic microstructure present in the as-cast material, see Fig. 13. The figure shows that the addition of $0.012 \mathrm{wt} \% \mathrm{Nb}$ to the composition refined the average effective grain size of the cast martensitic - bainitic microstructure by $35 \%$ which resulted a higher hardness level. (Here effective grain size means the equivalent circle diameter of grains enclosed by grain boundaries with a misorientation of $15^{\circ}$ or more). 
In order to reveal the parent austenite grain structure, the EBSD data was subjected to a reconstruction technique that employed Matlab supplemented with the MTEX texture and crystallography analysis toolbox [59]. Briefly, grain maps were initially assembled from the data sets with a grain boundary tolerance of 3 degrees. Subsequently, the parent austenite orientation map was reconstructed from this data with a two-step reconstruction algorithm. In the first step, the orientation relationship between austenite and martensite was determined from intergranular misorientations following the procedure proposed by Nyyssönen et al. [60]. In the second step, the grain map was divided into discrete clusters using the Markov clustering method [60] proposed by Gomes and Kestens [61]. The parent austenite orientation was then calculated for each cluster separately, resulting in a reconstructed orientation map. The average misorientation between the reconstructed orientation for each cluster and the best fit for each individual grain was approximately 2 degrees, indicating a good fit for the reconstructed result. The full details for the reconstructed procedure are available in Reference [62].

It should be noted that since the as-cast austenite grain diameters were really large, it was not possible to image whole grains in the FESEM even using the lowest possible magnification giving sufficiently confident indexing of the EBSD data. Therefore, a series of 18 images has been stitched together to obtain the overall images in Fig. 13. According to the IDS software, an addition of $0.012 \mathrm{wt}$ \% $\mathrm{Nb}$ should reduce the prior austenite grain size only slightly from $1700 \mu \mathrm{m}$ to $1638 \mu \mathrm{m}$. On the basis of the reconstructed austenite grains shown in Fig. 13 (c and c'), it would appear that the effect of Nb on the austenite grain size is, however, greater than predicted. It has to be noted that in the grain map with IPF (inverse pole figure) colouring, the green lines are the grain boundaries with a special misorientation angle like thermal twin boundaries.

The observed refining effects of the small addition of $\mathrm{Nb}$ on the prior austenite grain size and the effective grain size of the as-cast martensitic-bainitic microstructure are expected to be beneficial in slab handling and reheating prior to hot rolling. The finer grain sizes can be expected to translate into improved toughness of the slabs. Differential thermal expansion stresses can cause cracking during the reheating of high-strength slab material. Since the occurrence of such cracking can have serious financial consequences for the steel producer, the use of a microaddition of $\mathrm{Nb}$ is expected to be valuable from this point of view, too.

In order to study the role that $\mathrm{Nb}$ will have during slab reheating prior to hot rolling, some as-cast specimens were quenched in water after reheating to $1200{ }^{\circ} \mathrm{C}$ for $3 \mathrm{~h}$. The reconstructed reheated austenite grain structure is presented in Fig. 14. It is clear that the sample containing $\mathrm{Nb}$ has a finer grain structure.

\section{4-3-Cooling rates and related hardness}

As one of the objectives of this work was the attainment of a given hardenability, it was important to compare measured and predicted hardness and microstructures as a function of cooling rate. To do this, hot rolled samples of the Nb-microalloyed composition were austenitized at $950{ }^{\circ} \mathrm{C}$ and then quenched with two different cooling rates. The prior austenite grain size after this heat treatment was $20 \mu \mathrm{m}$ as presented in Fig. 15(d). The 
results agreed well with the predicted outcomes, which were also based on an austenite grain size of $20 \mu \mathrm{m}$, i.e. ASTM 8. The contents of chromium and molybdenum were optimised to avoid the formation of ferrite and bainite under cooling rates of 10 and $45^{\circ} \mathrm{C} / \mathrm{s}$, respectively. In agreement with the calculations, the microstructure of the sample quenched at $10^{\circ} \mathrm{C} / \mathrm{s}$ did not contain any ferrite, as shown in Fig. 15(b). It comprised a mixture of bainite and martensite with bulk hardness of $519 \pm 5 \mathrm{HV}$ compared with the predicted value of 509 $\mathrm{HV}$. In the same way, a fully martensitic microstructure was produced after cooling at 45 ${ }^{\circ} \mathrm{C} / \mathrm{s}$, as presented in Fig. 15(c). In this case the measured hardness was $628 \pm 2 \mathrm{HV}$, which is very close to the predicted $626 \mathrm{HV}$, Fig. 15(a).

\section{4-4- Microsegregation}

The microsegregation of $\mathrm{Nb}$ in the sample containing $0.012 \mathrm{wt} \% \mathrm{Nb}$ was studied using EPMA step scanning at the center of the casting and near the chilled zone, see Fig. 16. The step length was $10 \mu \mathrm{m}$ and the number of steps per line was 100 making each line $1000 \mu \mathrm{m}$ long, which thereby crossed several dendrites. The positions of the scanned lines could not be specifically positioned relative to the dendritic structure, so the highest concentration peaks need not have been encountered as frequently as the secondary dendrite arm spacing. Looking at the EPMA results in Fig. 16, apart from the two highest peaks, peak concentrations are generally approximately $0.03 \mathrm{wt} . \%$, which is close to that predicted by the IDS software (see results for 0.012 wt.\% Nb in Fig. 8). However, it is apparent that there are places in the centre of the ingot with very high concentrations of $\mathrm{Nb}$ that even exceed $0.1 \mathrm{wt} . \%$. These are probably associated with larger regions of macrosegregation that are less affected by back diffusion during the cooling of the ingot.

\section{5- Conclusions}

Metallurgical principles assisted by computational thermodynamics and kinetics have been used to design the chemical composition of a novel steel for wear resistant applications such as slurry transportation pipelines. Commercial software packages for the thermodynamics and kinetics of phase transformations and diffusion, namely Thermo-Calc ${ }^{\circledR}$ and $\mathrm{JMatPro}^{\circledR}$, have been combined with the interdendritic segregation tool IDS to optimize the contents of chromium, molybdenum and niobium in a medium-carbon low-manganese steel composition. The optimization procedure resulted in the following bulk chemical composition (in wt. \%): $0.40 \mathrm{C}, 0.20 \mathrm{Si}, 0.25 \mathrm{Mn}, 0.90 \mathrm{Cr}, 0.50 \mathrm{Mo}, 0.012 \mathrm{Nb}$. The major conclusions are the following:

1- The applied composition design methodology and experimental results demonstrate how desired properties in a new steel composition can be reached using combinations of different thermo-kinetic computational software packages.

2- Confirmation experiments verified the accuracy of input variables like dendrite arm spacing and austenite grain size, and confirmed the reliability of the computational calculations. Heat treated samples showed that the suggested optimum composition met the predicted hardness and hardenability properties. In the case of an austenite grain size of ASTM 8, the composition was fully hardened with the cooling rate of 45 ${ }^{\circ} \mathrm{C} / \mathrm{s}$ as predicted. A final bulk hardness of $628 \pm 2 \mathrm{HV}$ was achieved where the predicted value was $626 \mathrm{HV}$. 
3- Regarding $\mathrm{Nb}$ microsegregation profiles, the predictions of the interdendritic solidification tool IDS were in close agreement with measurements on as-cast material. However, the IDS predictions underestimated the refining effect of $\mathrm{Nb}$ on the as-cast austenite grain size.

4- In addition to its effect on prior austenite grain size, the microaddition of $\mathrm{Nb}$ refined the effective grain size of the as-cast bainitic - martensitic microstructure, which is expected to have beneficial consequences regarding the susceptibility of cast slabs to brittle fracture during reheating prior to hot rolling.

\section{6- Acknowledgements}

The authors are grateful for financial support from the European Commission under grant number 675715 - MIMESIS - H2020-MSCA-ITN-2015, which is a part of the Marie Sklodowska-Curie Innovative Training Networks European Industrial Doctorate programme. We would also like to thank Sami Koskenniska of the University of Oulu for providing some of the IDS simulations.

\section{7- References}

[1] L.M. Gil-Martín, M.J. González-López, A. Grindlay, A. Segura-Naya, M.A. Aschheim, E. Hernández-Montes, Toward the production of future heritage structures: Considering durability in building performance and sustainability - A philosophical and historical overview, Int. J. Sustain. Built Environ. 1 (2012) 269-273. doi:10.1016/j.ijsbe.2013.02.001.

[2] B. Rossi, Discussion on the use of stainless steel in constructions in view of sustainability, Thin-Walled Struct. 83 (2014) 182-189. doi:10.1016/j.tws.2014.01.021.

[3] B.A. Burgan, M.R. Sansom, Sustainable steel construction, J. Constr. Steel Res. 62 (2006) 1178-1183. doi:10.1016/j.jcsr.2006.06.029.

[4] H. Wu, B. Ju, D. Tang, R. Hu, A. Guo, Q. Kang, D. Wang, Effect of Nb addition on the microstructure and mechanical properties of an $1800 \mathrm{MPa}$ ultrahigh strength steel, Mater. Sci. Eng. A. 622 (2015) 61-66. doi:10.1016/j.msea.2014.11.005.

[5] M. Delincé, Y. Bréchet, J.D. Embury, M.G.D. Geers, P.J. Jacques, T. Pardoen, Structureproperty optimization of ultrafine-grained dual-phase steels using a microstructure-based strain hardening model, Acta Mater. 55 (2007) 2337-2350. doi:10.1016/j.actamat.2006.11.029.

[6] N. Zhong, X.D. Wang, L. Wang, Y.H. Rong, Enhancement of the mechanical properties of a $\mathrm{Nb}$-microalloyed advanced high-strength steel treated by quenching-partitioning-tempering process, Mater. Sci. Eng. A. 506 (2009) 111-116. doi:10.1016/j.msea.2008.11.014.

[7] A.A. Barani, F. Li, P. Romano, D. Ponge, D. Raabe, Design of high-strength steels by microalloying and thermomechanical treatment, Mater. Sci. Eng. A. 463 (2007) 138-146. doi:10.1016/j.msea.2006.08.124.

[8] R.J. Llewellyn, S.K. Yick, K.F. Dolman, Scouring erosion resistance of metallic materials 
used in slurry pump service, Wear. 256 (2004) 592-599. doi:10.1016/j.wear.2003.10.002.

[9] R. Hamzah, D.J. Stephenson, J.E. Strutt, Erosion of material used in petroleum production, Wear. 186-187 (1995) 493-496. doi:10.1016/0043-1648(95)07127-X.

[10] F. Aiming, L. Jinming, T. Ziyun, Failure analysis of the impeller of a slurry pump subjected to corrosive wear, Wear. 181-183 (1995) 876-882. doi:10.1016/0043-1648(95)90210-4.

[11] R. Macchini, M.S.A. Bradley, T. Deng, Influence of particle size, density, particle concentration on bend erosive wear in pneumatic conveyors, Wear. 303 (2013) 21-29. doi:10.1016/j.wear.2013.02.014.

[12] A. V. Levy, The solid particle erosion behavior of steel as a function of microstructure, Wear. 68 (1981) 269-287. doi:10.1016/0043-1648(81)90177-0.

[13] T. Foley, A. Levy, The erosion of heat-treated steels, Wear. 91 (1983) 45-64. doi:10.1016/0043-1648(83)90107-2.

[14] G.L. Sheldon, Effects of Surface Hardness and Other Material Properties on Erosive Wear of Metals by Solid Particles, J. Eng. Mater. Technol. 99 (1977) 133. doi:10.1115/1.3443422.

[15] D.J. O’Flynn, M.S. Bingley, M.S.A. Bradley, A.J. Burnett, A model to predict the solid particle erosion rate of metals and its assessment using heat-treated steels, Wear. 248 (2001) 162-177. doi:10.1016/S0043-1648(00)00554-8.

[16] J. Elliott, Pipe Systems: Under Attack from Multiple Directions, Power Eng. -Barringt. Then Tulsa. 24-30 (2011) 1-2.

[17] J.G. Williams, Advances in steels for high strength ERW linepipe application in Australia, Mater. Forum. 31 (2007) 1-10.

[18] K.-E. Thelning, Steel and its Heat Treatment, Second, Elsevier, 1984.

[19] J.K. Odusote, T.K. Ajiboye, A.B. Rabiu, Evaluation of Mechanical Properties of Medium Carbon Steel Quenched in Water and Oil, J. Miner. Mater. Charact. Eng. 11 (2012) 859-862. doi:10.4236/jmmce.2012.119079.

[20] J.G. Speer, S.S. Hansen, Austenite recrystallization and carbonitride precipitation in niobium microalloyed steels, Metall. Trans. A. 20 (1989) 25-38. doi:10.1007/BF02647491.

[21] S.F. Medina, The influence of niobium on the static recrystallization of hot deformed austenite and on strain induced precipitation kinetics, Scr. Metall. Mater. 32 (1995) 43-48. doi:10.1016/S0956-716X(99)80009-0.

[22] H.E. Lippard, C.E. Campbell, V.P. Dravid, G.B. Olson, T. Björklind, U. Borggren, P. Kellgren, Microsegregation behavior during solidification and homogenization of AerMet100 steel, Metall. Mater. Trans. B. 29 (1998) 205-210. doi:10.1007/s11663-9980023-0.

[23] E. Kozeschnik, A scheil-gulliver model with back-diffusion applied to the microsegregation of chromium in Fe-Cr-C alloys, Metall. Mater. Trans. A. 31 (2000) 1682-1684. doi:10.1007/s11661-000-0179-y.

[24] Q. Chen, B. Sundman, Computation of Partial Equilibrium Solidification with Complete Interstitial and Negligible Substitutional Solute Back Diffusion, Mater. Trans. 43 (2002) 
551-559. doi:10.2320/matertrans.43.551.

[25] J. Miettinen, S. Louhenkilpi, H. Kytönen, J. Laine, IDS: Thermodynamic-kinetic-empirical tool for modelling of solidification, microstructure and material properties, Math. Comput. Simul. 80 (2010) 1536-1550. doi:10.1016/j.matcom.2009.11.002.

[26] F. Han, B. Hwang, D.-W. Suh, Z. Wang, D.L. Lee, S.-J. Kim, Effect of molybdenum and chromium on hardenability of low-carbon boron-added steels, Met. Mater. Int. 14 (2008) 667. doi:10.3365/met.mat.2008.12.667.

[27] K. Junhua, Z. Lin, G. Bin, L. Pinghe, W. Aihua, X. Changsheng, Influence of Mo content on microstructure and mechanical properties of high strength pipeline steel, Mater. Des. 25 (2004) 723-728. doi:10.1016/j.matdes.2004.03.009.

[28] M. Calcagnotto, D. Ponge, D. Raabe, Effect of grain refinement to $1 \mu \mathrm{m}$ on strength and toughness of dual-phase steels, Mater. Sci. Eng. A. 527 (2010) 7832-7840. doi:10.1016/j.msea.2010.08.062.

[29] Y. Xia, L. Yulong, L. Li, Effect of Grain Refinement on Fracture Toughness and Fracture Mechanism in AZ31 Magnesium Alloy, Procedia Mater. Sci. 3 (2014) 1780-1785. doi:10.1016/j.mspro.2014.06.287.

[30] T. Shimokawa, M. Tanaka, K. Kinoshita, K. Higashida, Roles of grain boundaries in improving fracture toughness of ultrafine-grained metals, Phys. Rev. B. 83 (2011) 214113. doi:10.1103/PhysRevB.83.214113.

[31] A. Calik, A. Duzgun, O. Sahin, N. Ucar, Effect of Carbon Content on the Mechanical Properties of Medium Carbon Steels, Zeitschrift Für Naturforsch. A. 65 (2010). doi:10.1515/zna-2010-0512.

[32] H.K.D.H. Bhadeshia, D. Suh, Is a low-phosphorus content in steel a product requirement?, Ironmak. Steelmak. 42 (2015) 259-267.

[33] A.. Wang, Y.. Li, C.. Fan, K. Yang, D.. Li, X. Zhao, C.. Shi, Effect of p and Si(Mn) on the solidification segregation in an iron-based superalloy, Scr. Metall. Mater. 31 (1994) 16951700. doi:10.1016/0956-716X(94)90466-9.

[34] R.A. Mesquita, H.J. Kestenbach, On the effect of silicon on toughness in recent high quality hot work steels, Mater. Sci. Eng. A. 528 (2011) 4856-4859. doi:10.1016/j.msea.2011.02.065.

[35] R.A. Mesquita, C.A. Barbosa, E. V. Morales, H.J. Kestenbach, Effect of silicon on carbide precipitation after tempering of $\mathrm{H} 11$ hot work steels, Metall. Mater. Trans. A Phys. Metall. Mater. Sci. 42 (2011) 461-472. doi:10.1007/s11661-010-0430-0.

[36] P.P. Suikkanen, A.-J. Ristola, A.M. Hirvi, P. Sahu, M.C. Somani, D.A. Porter, L.P. Karjalainen, Effects of Carbon Content and Cooling Path on the Microstructure and Properties of TRIP-aided Ultra-High Strength Steels, ISIJ Int. 53 (2013) 337-346. doi:10.2355/isijinternational.53.337.

[37] D. Hejazi, A. Calka, D. Dunne, E. Pereloma, Effect of gaseous hydrogen charging on the tensile properties of standard and medium Mn X70 pipeline steels, Mater. Sci. Technol. 32 (2016) 675-683. doi:10.1080/02670836.2015.1130331.

[38] G. Krauss, Solidification, segregation, and banding in carbon and alloy steels, Metall. Mater. Trans. B. 34 (2003) 781-792. doi:10.1007/s11663-003-0084-Z. 
[39] T. Lis, Modification of oxygen and sulphur inclusions steel by calcium treatment, Metalurgija. 48 (2009) 95-98.

[40] J.G. Williams, New alloy design perspectives for high strength steels, in: Thermomechanical Process. Steel, Padua, 2008.

[41] Z. Tang, W. Stumpf, The role of molybdenum additions and prior deformation on acicular ferrite formation in microalloyed Nb-Ti low-carbon line-pipe steels, Mater. Charact. 59 (2008) 717-728. doi:10.1016/j.matchar.2007.06.001.

[42] Y. Weng, H. Dong, Y. Gan, eds., Advanced Steels, Springer Berlin Heidelberg, Berlin, Heidelberg, 2011. doi:10.1007/978-3-642-17665-4.

[43] D.B. Rosado, W. De Waele, D. Vanderschueren, Latest developments in mechanical properties and metallurgical features of high strength line pipe steels, in: Sustain. Constr. Des., Ghent, 2013: pp. 1-10. doi:10.13140/2.1.4498.5287.

[44] Z. Zhang, Y. Liu, X. Liang, Y. She, The effect of Nb on recrystallization behavior of a Nb micro-alloyed steel, Mater. Sci. Eng. A. 474 (2008) 254-260. doi:10.1016/j.msea.2007.04.041.

[45] S. Bao, G. Zhao, C. Yu, Q. Chang, C. Ye, X. Mao, Recrystallization behavior of a Nbmicroalloyed steel during hot compression, Appl. Math. Model. 35 (2011) 3268-3275. doi:10.1016/j.apm.2011.01.024.

[46] D. Chakrabarti, C. Davis, M. Strangwood, Development of bimodal grain structures in Nbcontaining high-strength low-alloy steels during slab reheating, Metall. Mater. Trans. A Phys. Metall. Mater. Sci. 39 (2008) 1963-1977. doi:10.1007/s11661-008-9535-0.

[47] C.L. Davis, M. Strangwood, Preliminary study of the inhomogeneous precipitate distributions in Nb-microalloyed plate steels, J. Mater. Sci. 37 (2002) 1083-1090. doi:10.1023/A:1014342800399.

[48] V.K. Heikkinen, R.H. Packwood, ON THE OCCURRENCE OF Fe-NbC EUTECTIC IN NIOBIUM-BEARING MILD STEEL, Scand. J. Metall. 6 (1977) 170-175.

[49] S. Matsui, S. Sato, T. Tanaka, Lecture 1214 - The Iron and Steel Institute of Japan, in: 102nd ISIJ Meet., 1981.

[50] A.J. Deardo, Niobium in modern steels, Int. Mater. Rev. 48 (2003) 371-402. doi:10.1179/095066003225008833.

[51] J.M. Gray, S. V Subramanian, Niobium Microalloyed Line Pipe Steels: Technological Overview, (2013) V001T01A002. doi:10.1115/IOGPC2013-9828.

[52] H.L. Andrade, M.G. Akben, J.J. Jonas, Effect of Molybdenum, Niobium, and Vanadium on Static Recovery and Recrystallization and on Solute Strengthening in Microalloyed Steels, Metall. Mater. Trans. A. 14 (1983) 1967-1977.

[53] H. Mohrbacher, Synergies of niobium and boron microalloying in Molybdenum based bainitic and martensitic steels, Fundomentals Appl. Mo an Nb Alloy. High Perform. Steels. 1 (2014).

[54] K. Hulka, A. Kern, U. Schriever, Application of Niobium in Quenched and Tempered HighStrength Steels, Mater. Sci. Forum. 500-501 (2005) 519-526. 
[55] J.O. Andersson, T. Helander, L. Hoglund, P. Shi, B. Sundman, THERMO-CALC \& DICTRA, Computational Tools For Materials Science, Calphad. 26 (2002) 273-312. www.thermocalc.com.

[56] S. Kurokawa, J.E. Ruzzante, A.M. Hey, F. Dyment, Diffusion of Nb in Fe and Fe alloys, Met. Sci. 17 (1983) 433-438. doi:10.1179/030634583790420628.

[57] G.R. Desale, B.K. Gandhi, S.C. Jain, Improvement in the design of a pot tester to simulate erosion wear due to solid - liquid mixture, Wear. 259 (2005) 196-202. doi:10.1016/j.wear.2005.02.068.

[58] Y. Li, G. Wen, L. Luo, J. Liu, P. Tang, Study of austenite grain size of microalloyed steel by simulating initial solidification during continuous casting, Ironmak. Steelmak. 42 (2015) 41 48. doi:10.1179/1743281214Y.0000000197.

[59] T. Nyyssönen, M. Isakov, P. Peura, V.-T. Kuokkala, Iterative Determination of the Orientation Relationship Between Austenite and Martensite from a Large Amount of Grain Pair Misorientations, Metall. Mater. Trans. A. 47 (2016) 2587-2590. doi:10.1007/s11661016-3462-2.

[60] S. van Dongen, Graph Clustering by Flow Simulation, University of Utrecht, 2000.

[61] E. Gomes, L.A.I. Kestens, Fully automated orientation relationship calculation and prior austenite reconstruction by random walk clustering, IOP Conf. Ser. Mater. Sci. Eng. 82 (2015) 12059. doi:10.1088/1757-899X/82/1/012059.

[62] T. Nyyssönen, Quenching and Partitioning of High-Aluminum Steels, Tampere University of Technology, 2017. https://tutcris.tut.fi/portal/files/9350586/nyyss_nen_1451.pdf. 
Table 1. JMatPro predictions for different compositions ( $\mathrm{Cr}$ and Mo contents shown in Fig. 2).

\begin{tabular}{|c|c|c|c|c|c|c|c|c|}
\hline Alloy No. & $\begin{array}{c}\mathbf{M s} \\
{ }^{\circ} \mathbf{C}\end{array}$ & $\underset{{ }^{\circ} \mathbf{C} / \mathbf{s}}{\mathbf{C R}(\mathbf{F n})}$ & $\underset{{ }^{\circ} \mathrm{C} / \mathrm{s}}{\mathbf{C R}(\mathbf{B n})}$ & $\begin{array}{c}\text { tFn } \\
\text { s }\end{array}$ & $\begin{array}{c}\text { TFn } \\
{ }^{\circ} \mathbf{C}\end{array}$ & $\begin{array}{c}\mathrm{tBn} \\
\mathrm{s}\end{array}$ & $\begin{array}{c}\text { TBn } \\
{ }^{\circ} \mathbf{C}\end{array}$ & $\begin{array}{c}\text { Martensite } \\
\text { Hardness } \\
\text { (HV10) }\end{array}$ \\
\hline 1 & 362.2 & 200 & 100 & 2.46 & 610 & 1.85 & 515 & 630.77 \\
\hline 2 & 357.5 & 70 & 70 & 4.40 & 610 & 2.40 & 520 & 630.78 \\
\hline 3 & 352.9 & 63 & 15 & 11.66 & 620 & 2.96 & 510 & 630.79 \\
\hline 4 & 358.9 & 80 & 95 & 3.77 & 610 & 1.92 & 510 & 635.92 \\
\hline 5 & 354.4 & 35 & 71 & 7.88 & 610 & 2.55 & 510 & 633.85 \\
\hline 6 & 349.9 & 10 & 52 & 22.9 & 620 & 3.23 & 510 & 631.78 \\
\hline 7 & 345.5 & 2.5 & 45 & 77.74 & 630 & 3.97 & 510 & 629.29 \\
\hline 8 & 351.5 & 25 & 45 & 9.74 & 600 & 2.70 & 500 & 640.75 \\
\hline 9 & 347.0 & 7 & 35 & 31.34 & 610 & 3.50 & 500 & 636.74 \\
\hline 10 & 342.7 & 2 & 25 & 106.97 & 620 & 4.35 & 500 & 632.66 \\
\hline $\begin{array}{l}\text { Ms: Start ten } \\
\text { CR(Fn): Coo } \\
\text { CR(Bn): Co } \\
\text { tFn: Time to }\end{array}$ & $\begin{array}{l}\text { rature of } \\
\text { rate for } \\
\text { g rate fo } \\
\text { Ferritic }\end{array}$ & $\begin{array}{l}\text { ensite transfo } \\
\text { sing the Ferri } \\
\text { sing the Bain } \\
\text { at TFn (s). }\end{array}$ & $\begin{array}{l}\text { ation }\left({ }^{\circ} \mathrm{C}\right) \text {. } \\
\text { ose. } \\
\text { nose. }\end{array}$ & & & \multicolumn{3}{|c|}{$\begin{array}{l}\text { TFn: Temperature of the Ferritic nose }\left({ }^{\circ} \mathrm{C}\right) \\
\text { tBn: Time to the Bainitic nose at } \mathrm{TBn}(\mathrm{s}) . \\
\text { TBn: Temperature of the Bainitic nose }\left({ }^{\circ} \mathrm{C}\right) \text {. }\end{array}$} \\
\hline
\end{tabular}

Table 2. Considered bulk composition and predicted interdendritic composition (wt.\%).

\begin{tabular}{lccccccc}
\hline & C & Si & Mn & Cr & Mo & Nb & Fe \\
\hline $\begin{array}{l}\text { Considered bulk composition } \\
\begin{array}{l}\text { Predicted interdendritic } \\
\text { composition }\end{array}\end{array}$ & 0.40 & 0.20 & 0.25 & 0.90 & 0.50 & $\mathbf{0 . 0 1 2}$ & Bal. \\
\hline
\end{tabular}


Figure Captions:

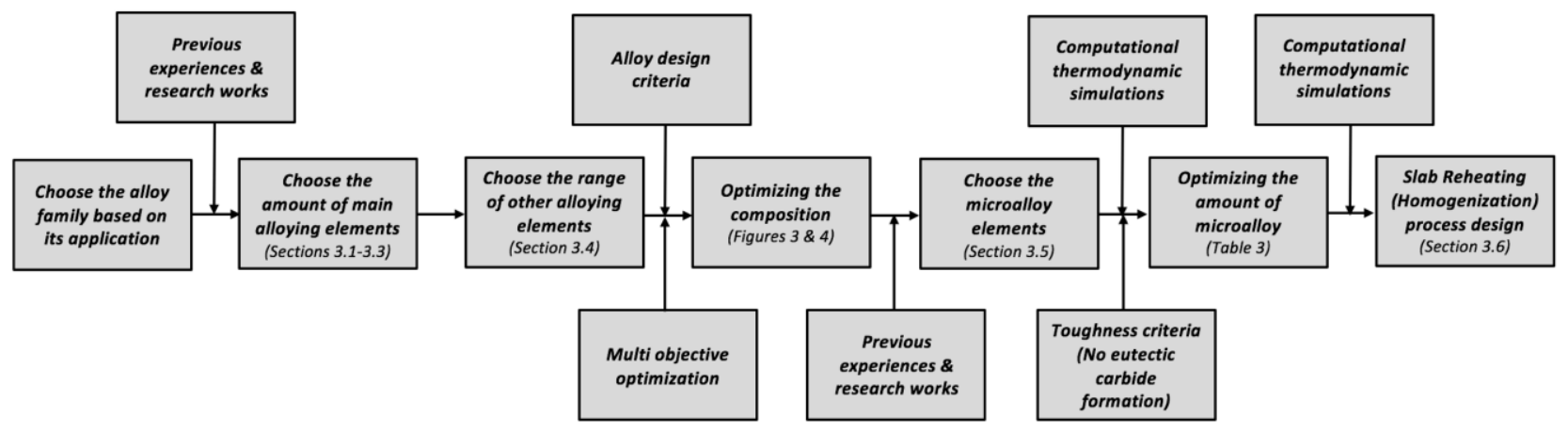

Figure 1. Flow chart showing the methodology applied in the composition design.

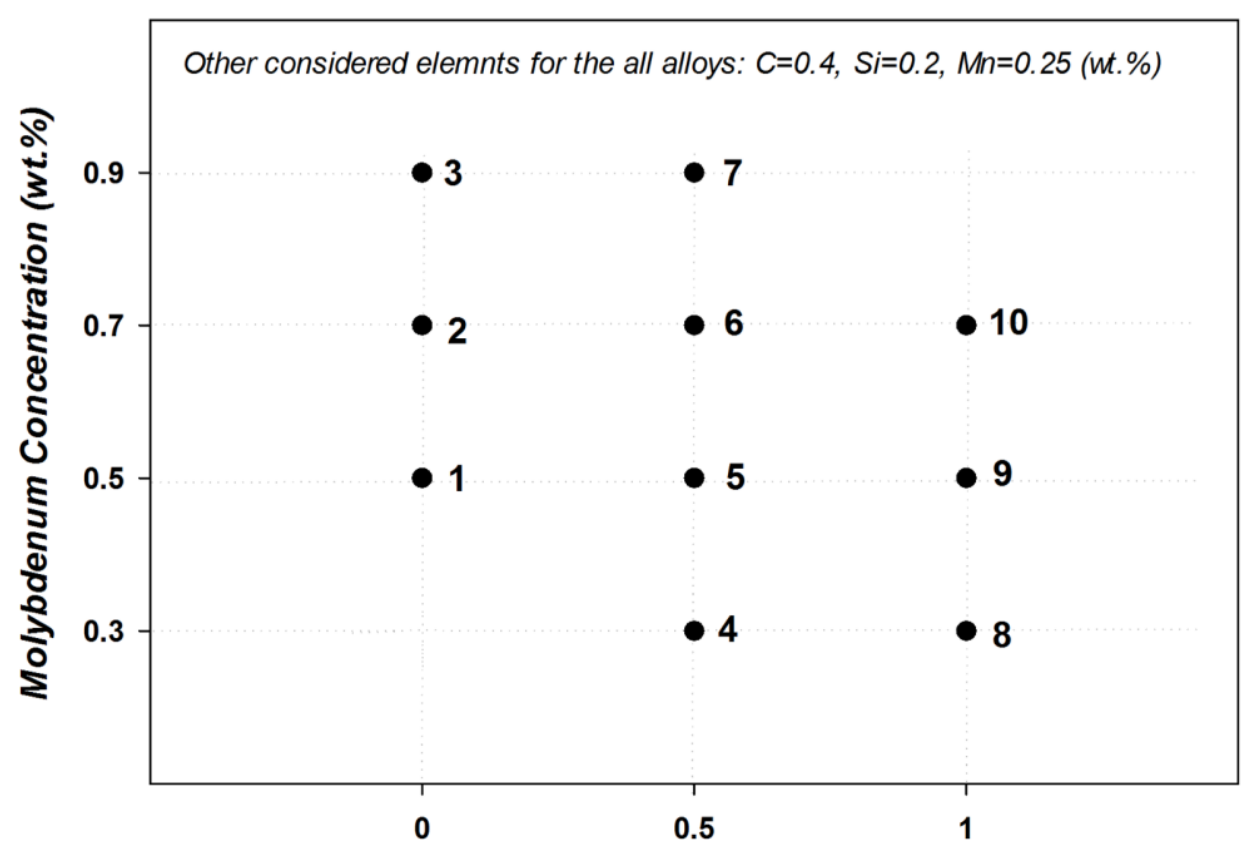

Chromium Concentration (wt.\%)

Figure 2. Alloy compositions considered in JMatPro CCT simulations. 


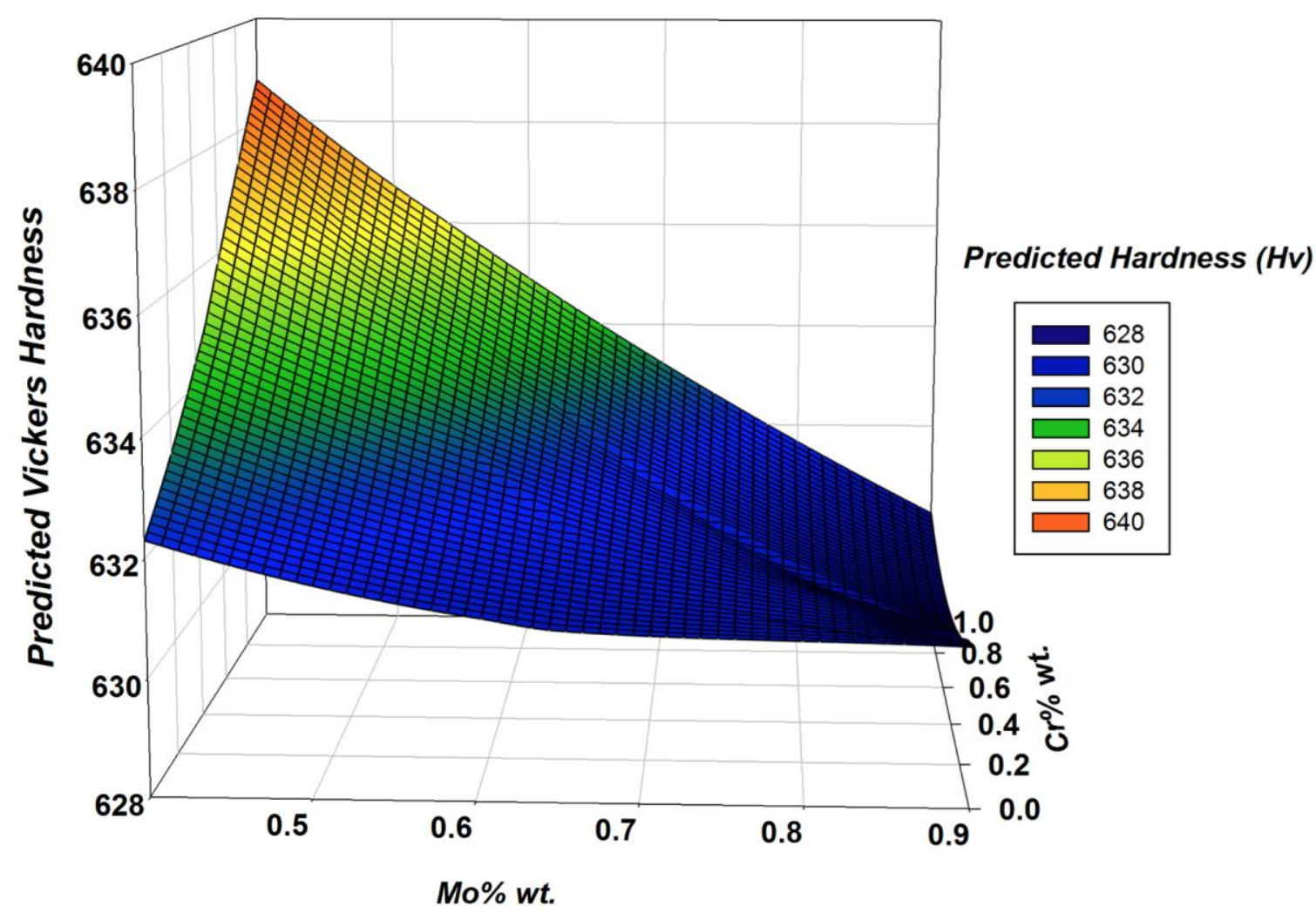

Figure 3. The predicted martensite hardness (HV) for different combinations of molybdenum and chromium contents. Other alloying elements: $0.4 \mathrm{C}, 0.25 \mathrm{Mn}, 0.2 \mathrm{Si}, 0.012 \mathrm{Nb}$.

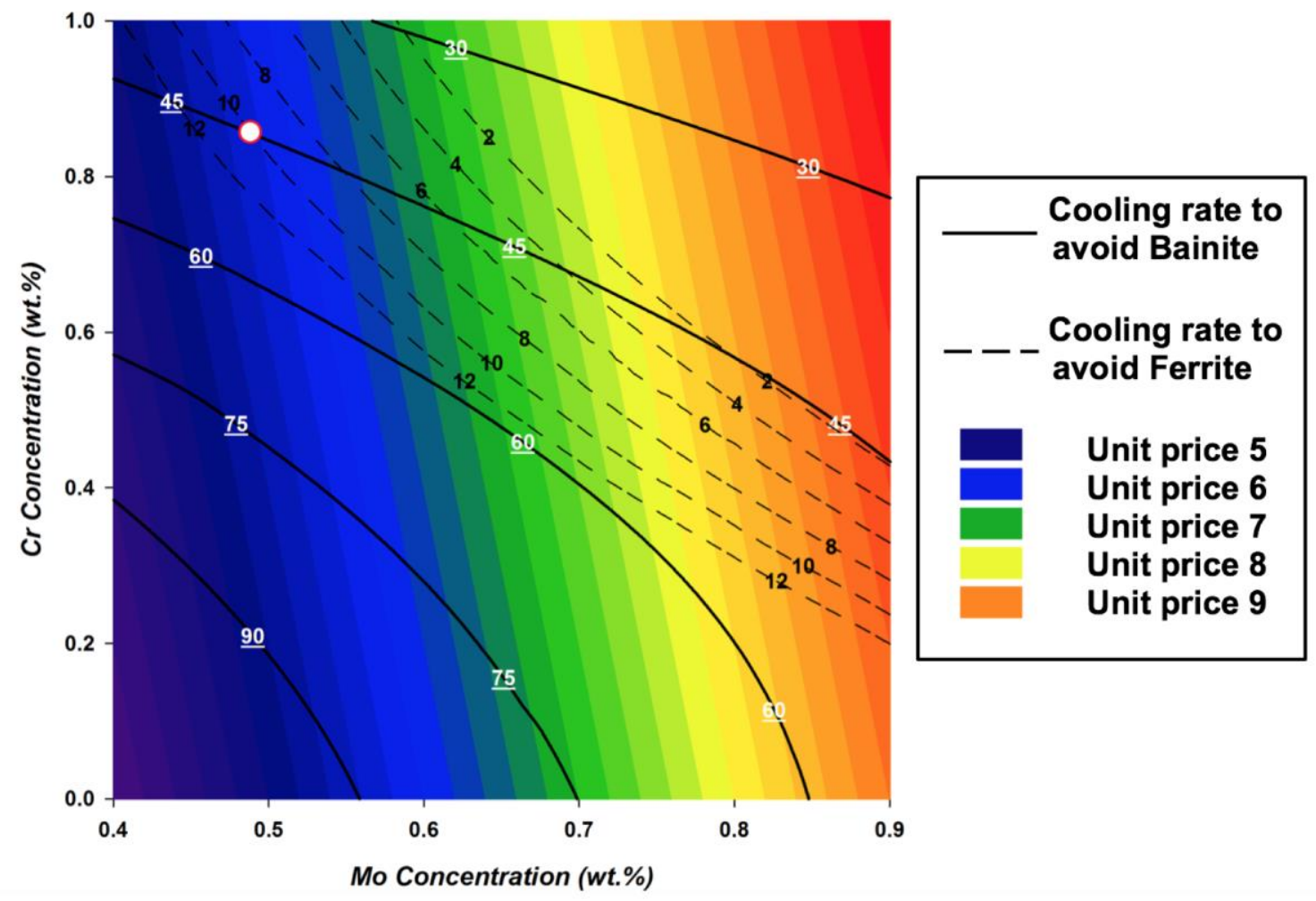

Figure 4. Effect of $\mathrm{Cr}$ and Mo content on the critical cooling rates in ${ }^{\circ} \mathrm{C} / \mathrm{s}$ to avoid bainite (solid line) and ferrite (dashed line) together with the relative cost of alloying on a mass basis assuming molybdenum is ten times more expensive than chromium (contour plot). The chosen composition is marked at $0.9 \% \mathrm{Cr}$ and $0.5 \% \mathrm{Mo}$. Other alloying elements: $0.4 \mathrm{C}, 0.25 \mathrm{Mn}, 0.2 \mathrm{Si}$, and $0.012 \mathrm{Nb}$. 


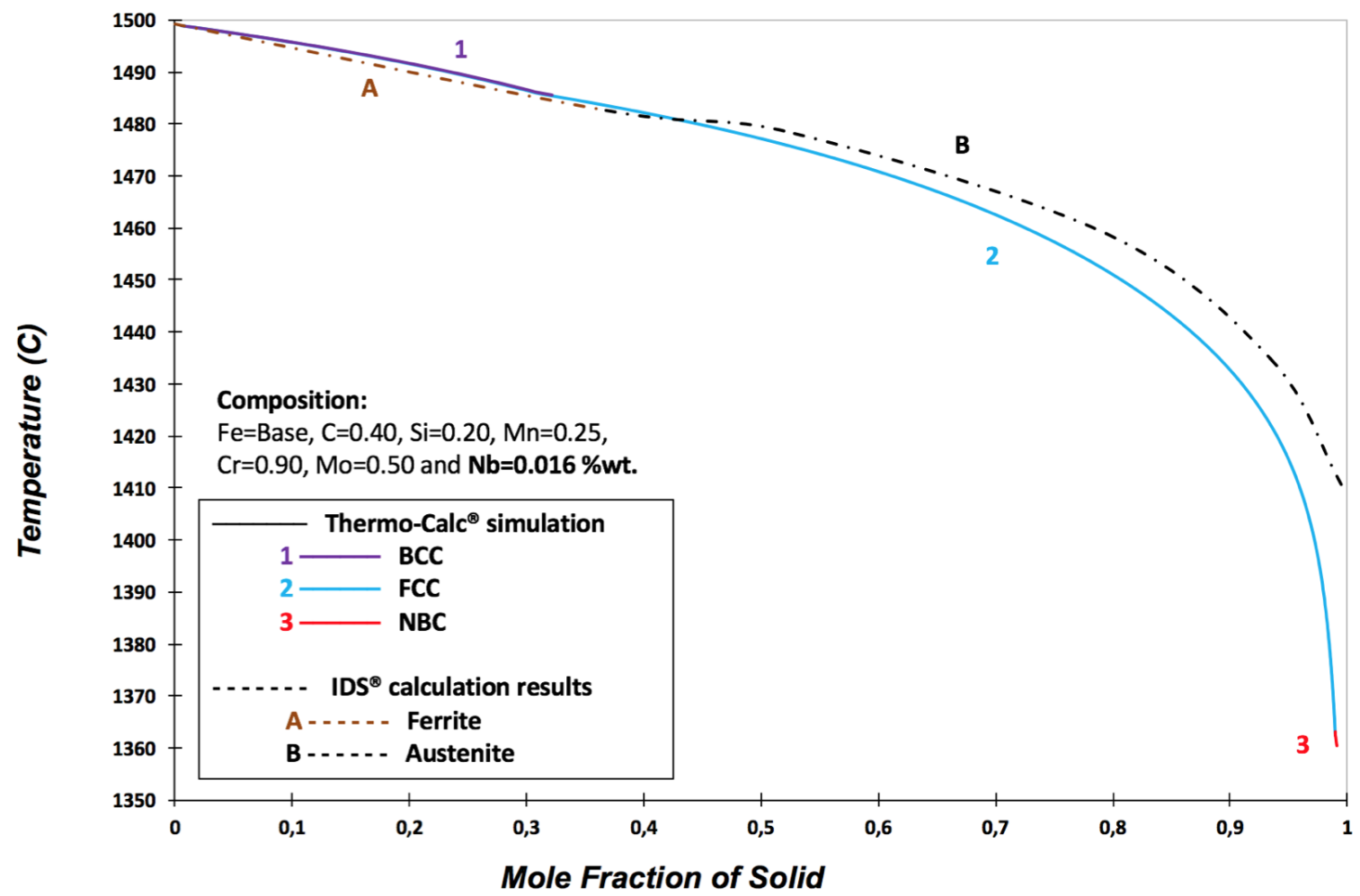

Figure 5. Solid fraction vs temperature curves for the composition $0.4 \mathrm{C}, 0.2 \mathrm{Si}, 0.25 \mathrm{Mn}, 0.9 \mathrm{Cr}, 0.5 \mathrm{Mo}$ and $0.016 \mathrm{Nb}$ wt.\% as predicted by Thermo-Calc and IDS assuming a cooling rate of $1^{\circ} \mathrm{C} / \mathrm{s}$ and a secondary dendrite arm spacing of $100 \mu \mathrm{m}$.

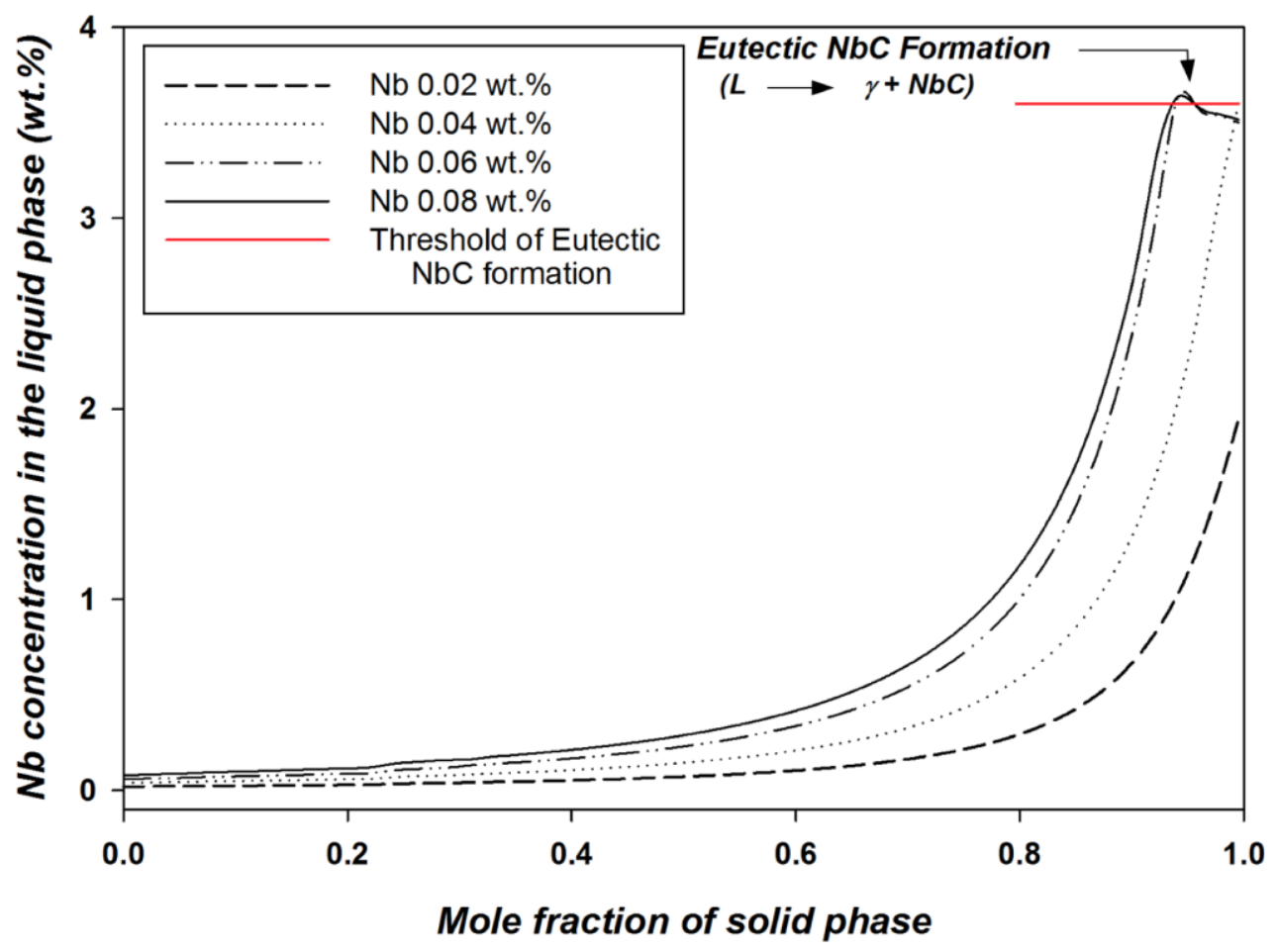

Figure 6. IDS calculations of Nb concentration in the liquid phase during solidification for different overall $\mathrm{Nb}$ contents. 


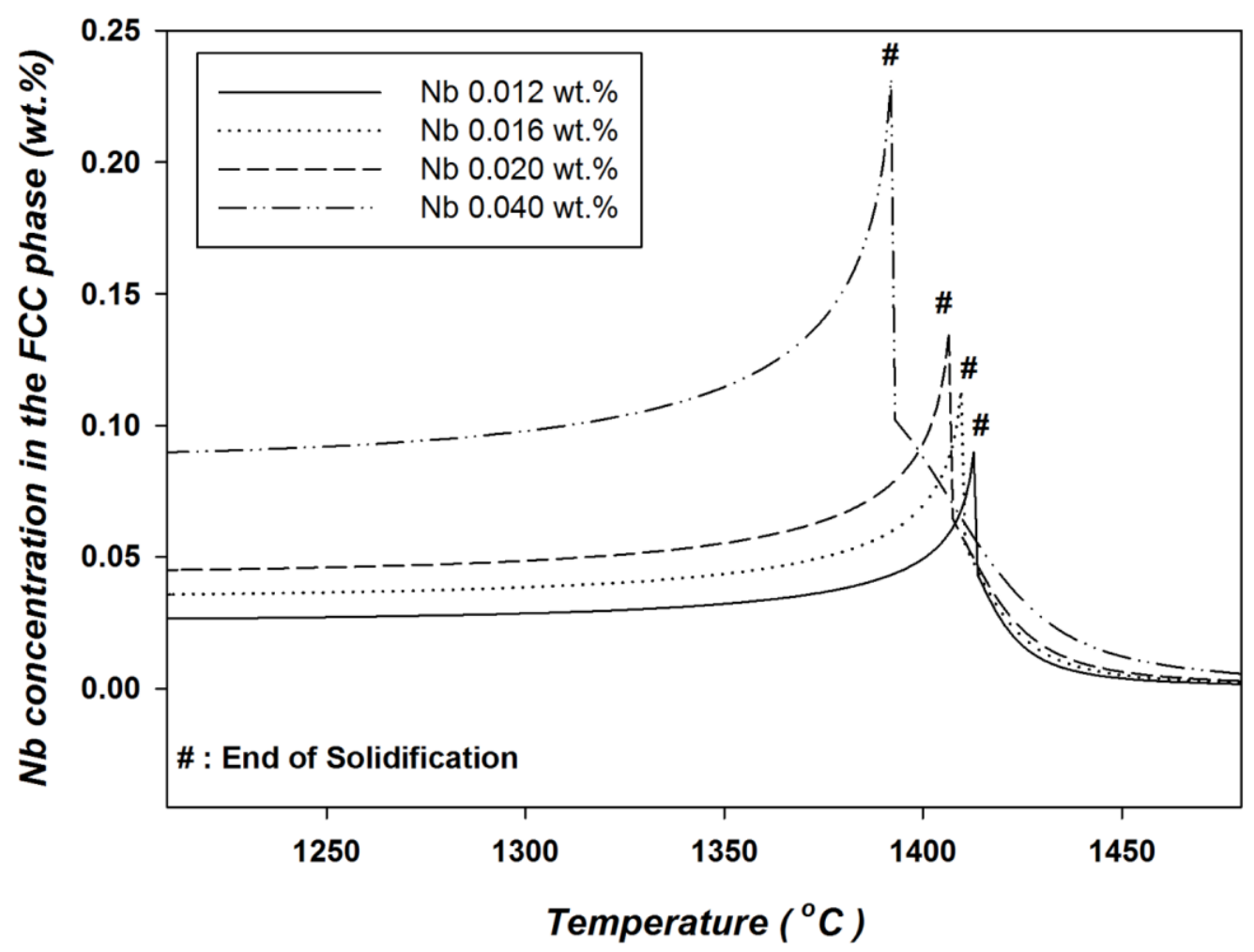

Figure 7. $\mathrm{Nb}$ concentration in the austenite formed from the interdendritic melt during solidification as a function of temperature, and, after the end of solidification, the concentration of $\mathrm{Nb}$ in the austenite in the last solid to form, i.e. in the interdendritic spaces, as a function of temperature. (Solidification to ferrite occurring above $1475^{\circ} \mathrm{C}$ is not shown). Cooling rate $1^{\circ} \mathrm{C} / \mathrm{s}$. Alloy contents other than $\mathrm{Nb}$ as given in Table 2(first row).

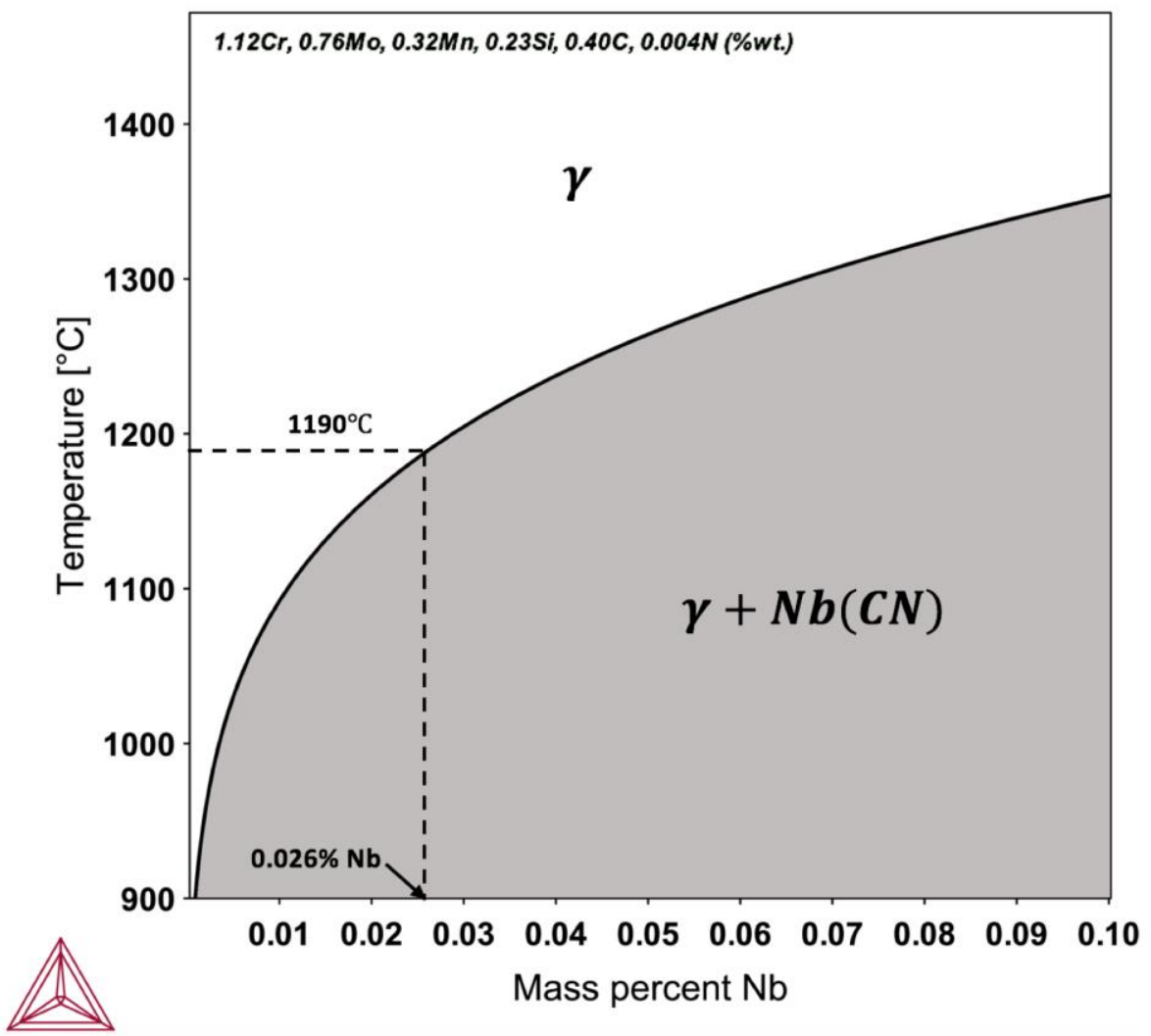

Figure 8. Phase diagram showing $\mathrm{Nb}$ solubility for the interdendritic austenite composition $(0.4 \mathrm{C}, 0.23 \mathrm{Si}, 0.32$ $\mathrm{Mn}, 1.12 \mathrm{Cr}, 0.76 \mathrm{Mo}, 0.004 \mathrm{~N}$ wt.\%). 


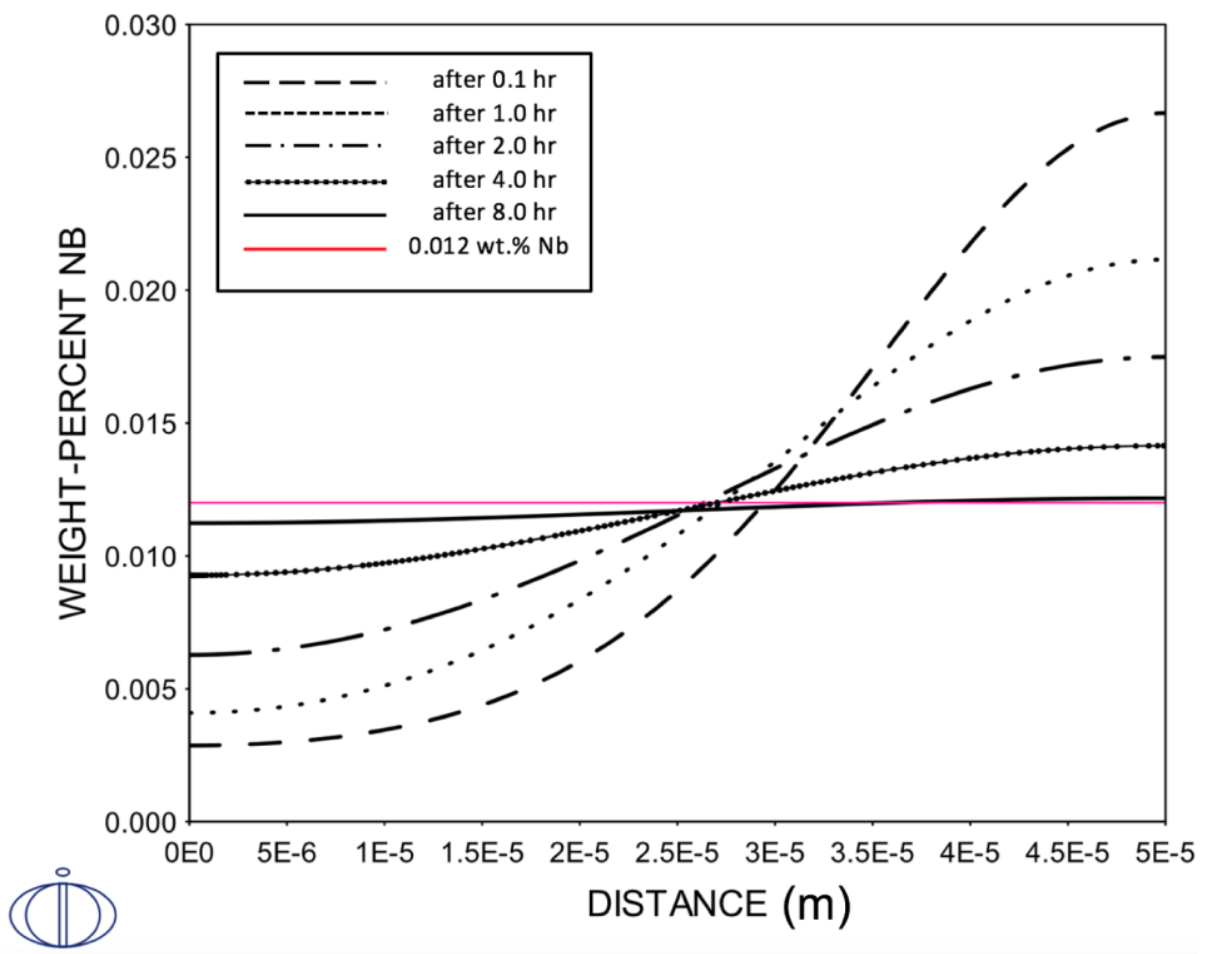

Figure 9. $\mathrm{Nb}$ concentration profile during the slab reheating for different holding time at $120{ }^{\circ} \mathrm{C}$.
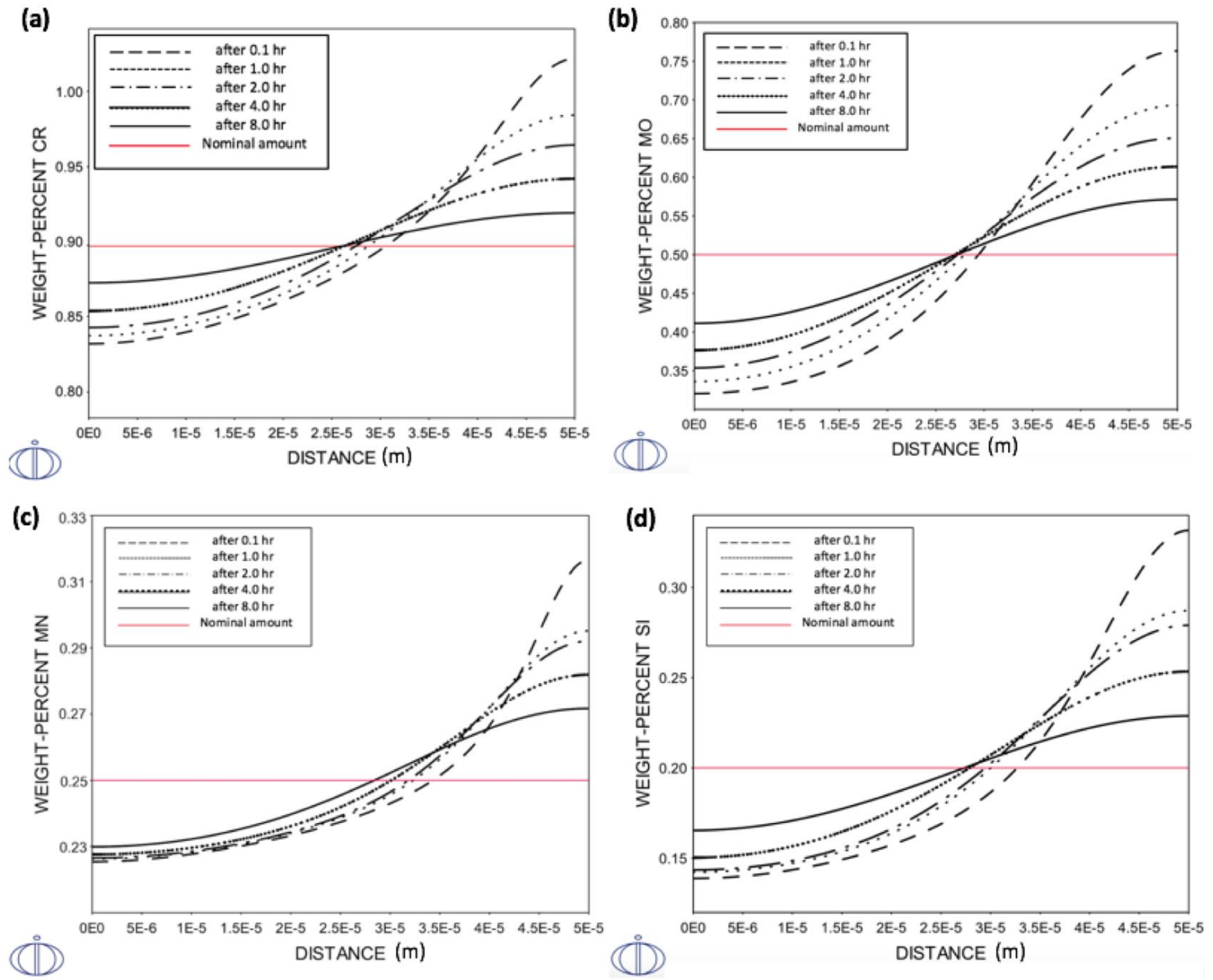

Figure 10. Predicted concentration profiles after slab reheating for various holding times at $1200{ }^{\circ} \mathrm{C}$. (a) $\mathrm{Cr}$, (b) Mo, (c) Mn and (d) Si. 


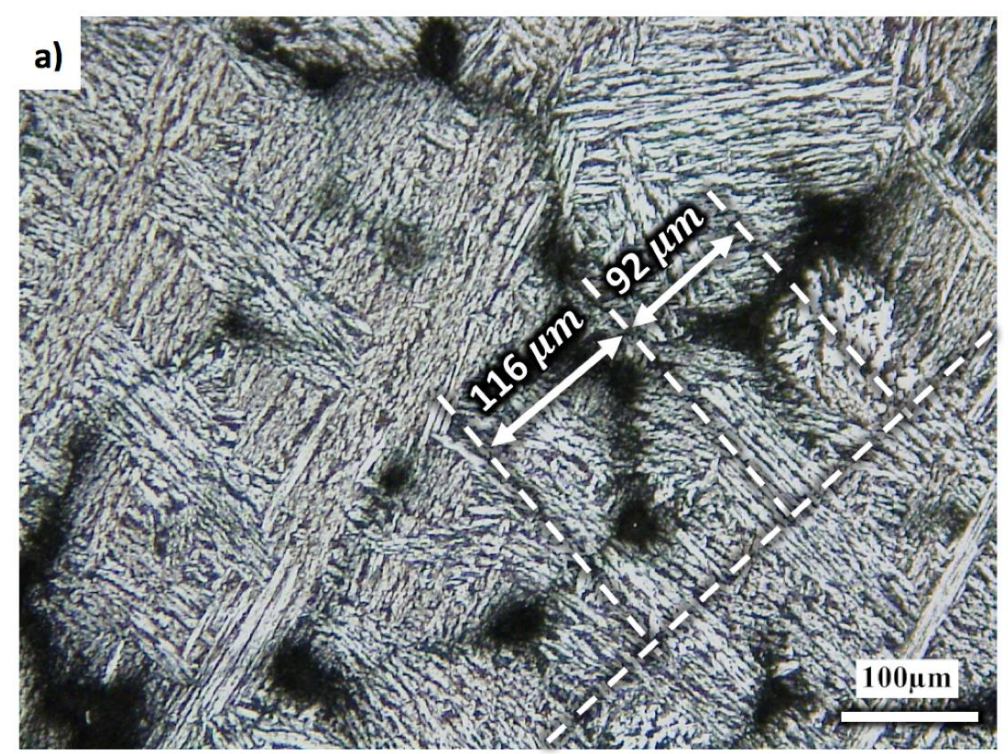

b)

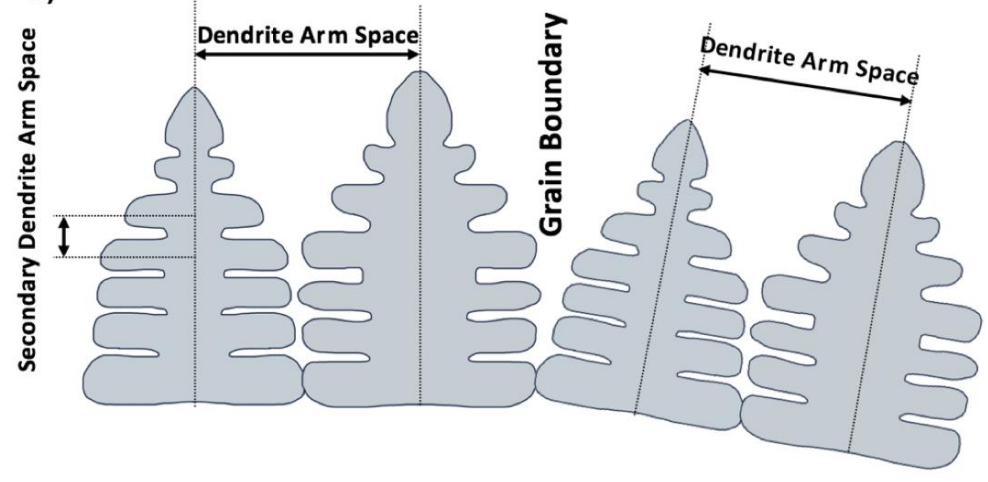

Figure 11. The dendritic structure of designed steel. a) Example of secondary dendrite arm spacing measurement, b) schematic illustration of dendrite growth.

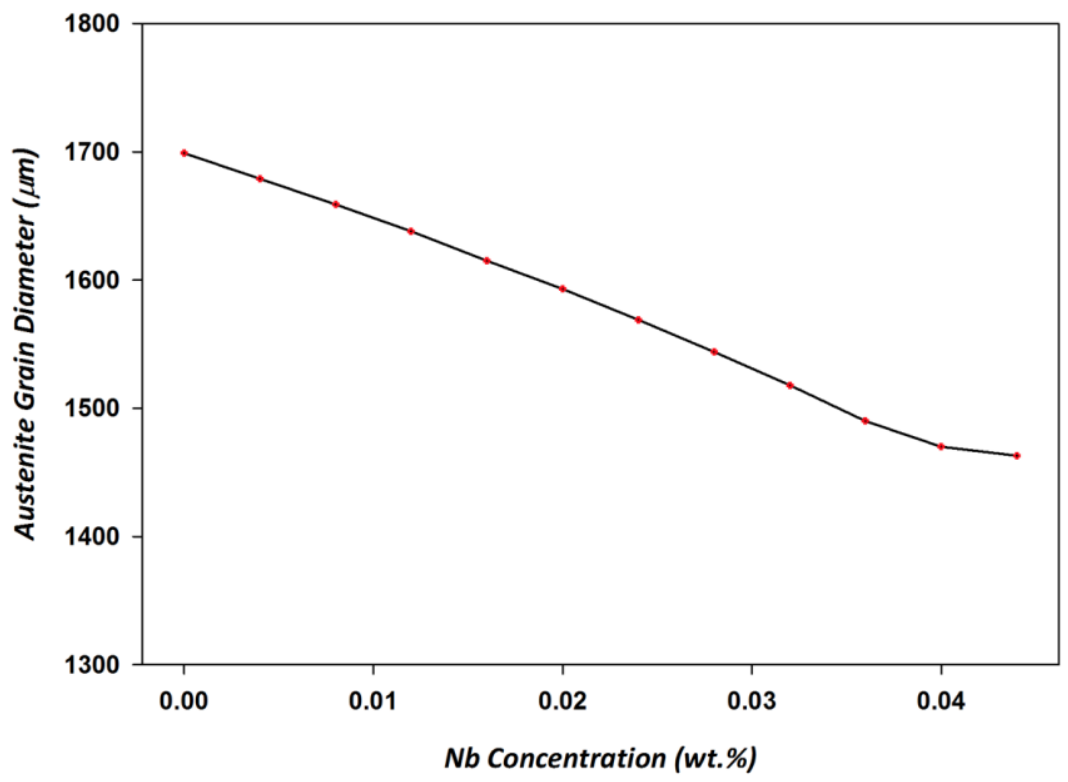

Figure 12. The as-cast prior austenite grain diameter predicted using the IDS software as function of $\mathrm{Nb}$ concentration for the composition $0.4 \mathrm{C}, 0.23 \mathrm{Si}, 0.32 \mathrm{Mn}, 1.12 \mathrm{Cr}, 0.76 \mathrm{Mo}, 0.004 \mathrm{~N}$ wt.\% (cooling rate $1^{\circ} \mathrm{C} / \mathrm{s}$ below $1600^{\circ} \mathrm{C}$ ). 

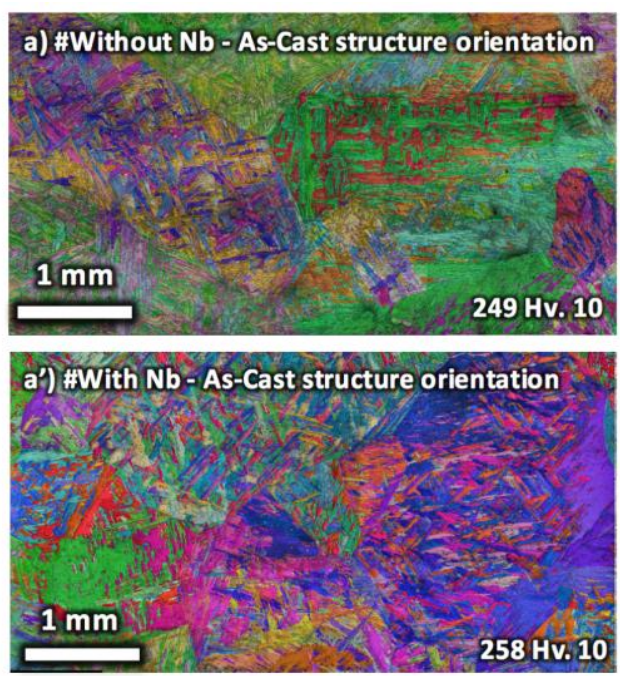
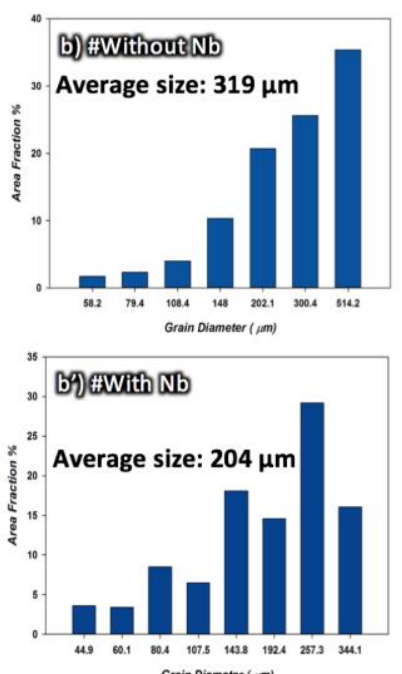
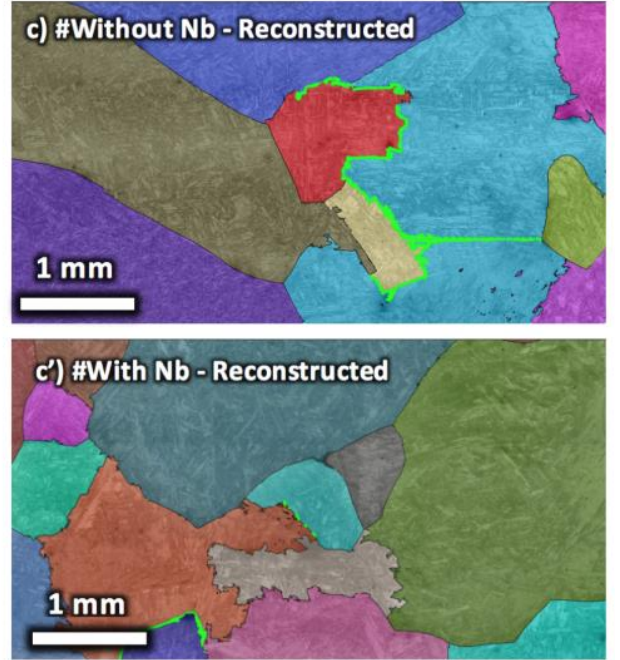

Figure 13. EBSD and austenite grain structure reconstruction results for an area exactly at the same position in the middle of each casting. ( $a, b$, and $c)$ chosen composition without $N b,\left(a^{\prime}, b^{\prime}, c^{\prime}\right)$ chosen composition containing Nb. (a and a') EBSD crystal orientation map merged with the image quality map. (b and $b^{\prime}$ ) grain size distribution histograms of as-cast bainitic ferrite microstructure, (c and $c^{\prime}$ ) reconstructed as-cast prior austenite grains.
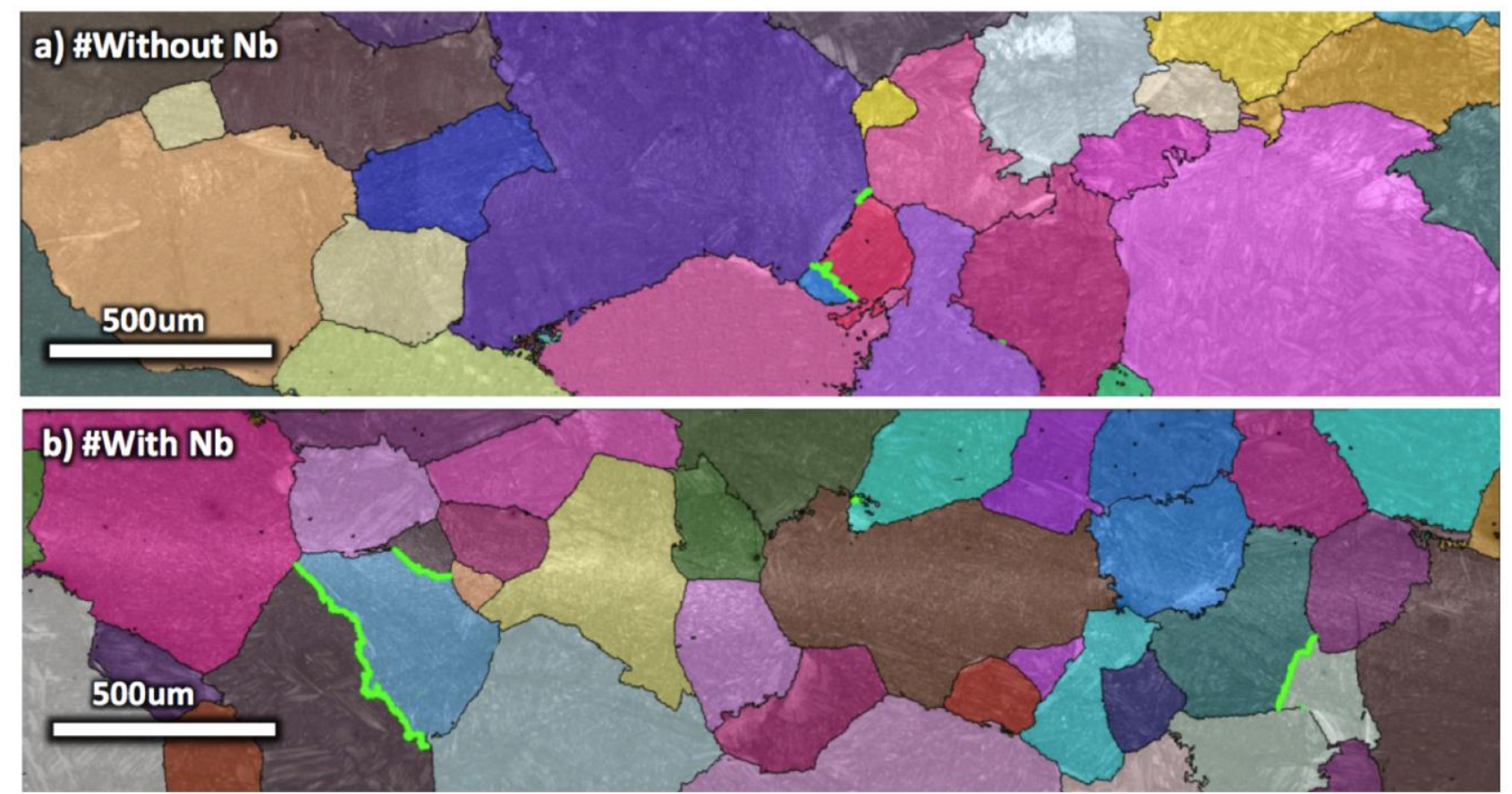

Figure 14. Prior austenite grain size after reheating at $1200^{\circ} \mathrm{C}$ for $3 \mathrm{hrs}$ and water quenching, a) without $\mathrm{Nb}$ and $\mathrm{b}$ ) with $\mathrm{Nb}$. 


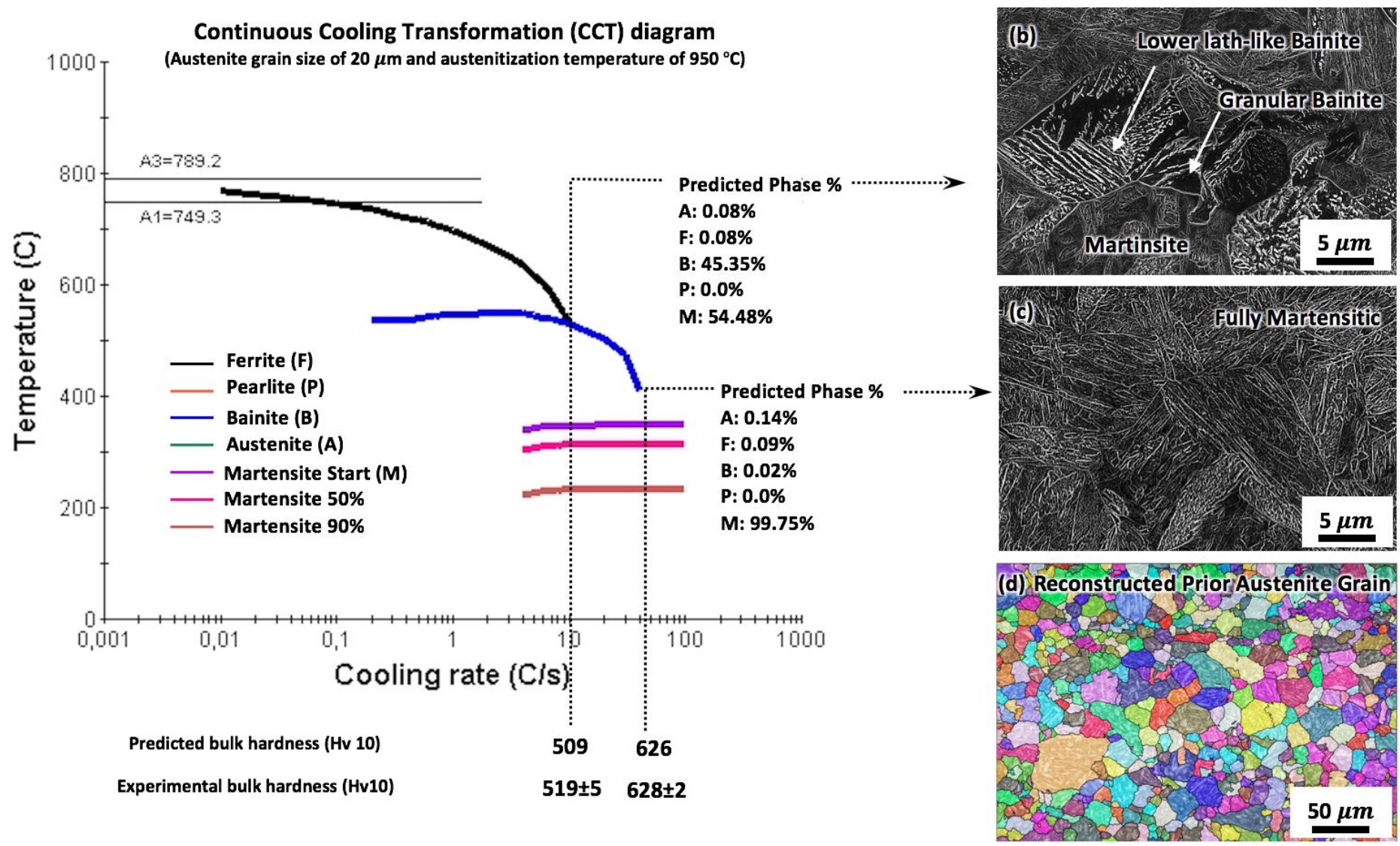

Figure 15. a) CCT diagrams calculated for the final chemical composition with $\mathrm{Nb}: 0.4 \mathrm{C}, 0.25 \mathrm{Mn}, 0.2 \mathrm{Si}, 0.012 \mathrm{Nb}$, $0.90 \mathrm{Cr}, 0.50 \mathrm{Mo} \mathrm{wt} . \%$. (Austenitization temperature of $950^{\circ} \mathrm{C}$ and average grain size $20 \mu \mathrm{m}$ ) containing predicted phase volume percentage for each cooling rate and bulk HV10 hardness values, b) microstructure of sample quenched under cooling rate of $45^{\circ} \mathrm{C} / \mathrm{s}, \mathrm{c}$ ) microstructure of sample quenched under cooling rate of $10^{\circ} \mathrm{C} / \mathrm{s}$ ), and d) the reconstructed prior austenite grain structure after induction hardening treatment. The predicted and experimental bulk hardness for the samples are given at the bottom of CCT diagram.

a)

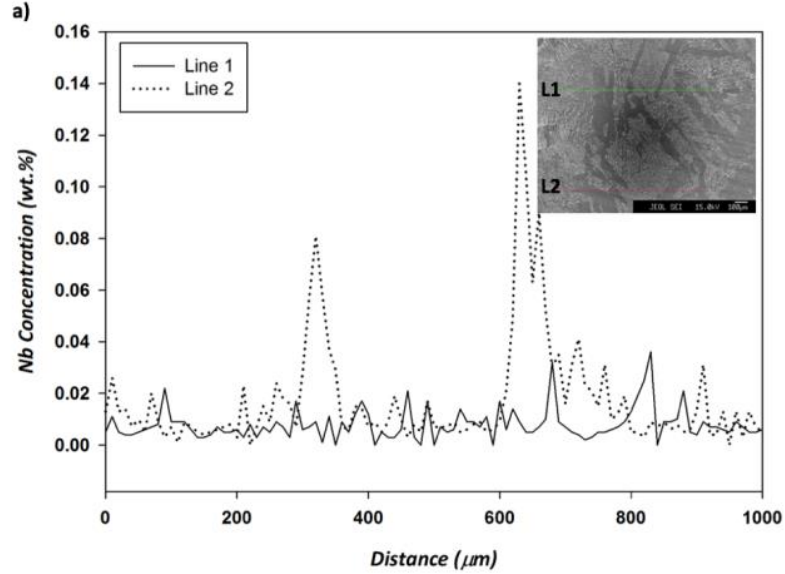

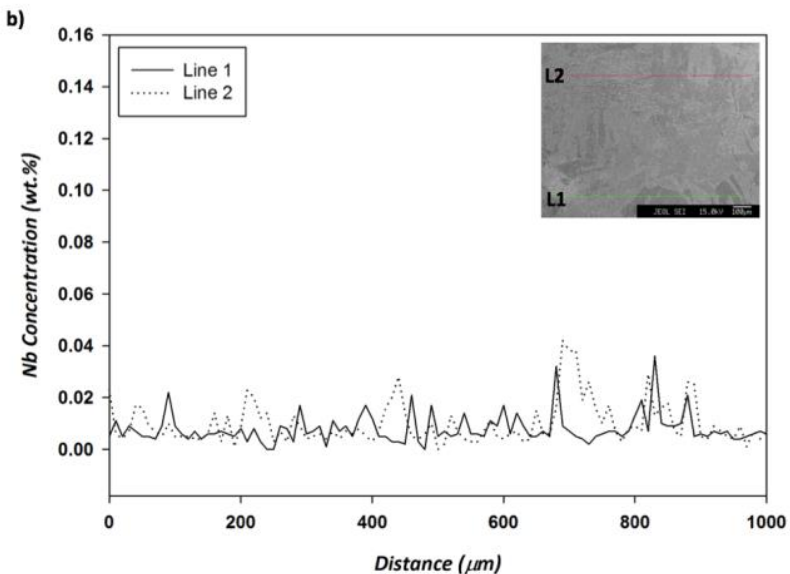

Figure 16. $\mathrm{Nb}$ concentration profile measured using EPMA for the sample selected from a) center-line of cast part, and b) near the mould surface (chill zone). 